Spring 4-24-2020

\title{
Exploring the Concurrent Validity of the Indoor Mobility Pre-driving Screen (IMPS): A Comparison of the IMPS and EF-Car Motion Driving Simulator.
}

\author{
Nicholas T. Bolen \\ University of St. Augustine for Health Sciences \\ DOI: https://doi.org/10.46409/sr.IPQQ7610
}

Follow this and additional works at: https://soar.usa.edu/capstones

Part of the Occupational Therapy Commons, and the Other Medicine and Health Sciences Commons

\section{Recommended Citation}

Bolen, N. T. (2020). Exploring the Concurrent Validity of the Indoor Mobility Pre-driving Screen (IMPS): A Comparison of the IMPS and EF-Car Motion Driving Simulator.. [Doctoral project, University of St Augustine for Health Sciences]. SOAR @ USA: Student Capstone Projects Collection. https://doi.org/ 10.46409/sr.IPQQ7610

This Capstone is brought to you for free and open access by the Student Research at SOAR @ USA. It has been accepted for inclusion in Student Capstone Projects by an authorized administrator of SOAR @ USA. For more information, please contact soar@usa.edu, erobinson@usa.edu. 
EXPLORING THE CONCURRENT VALIDITY OF THE INDOOR MOBILITY PREDRIVING SCREEN (IMPS): A COMPARISON OF THE IMPS AND EF-CAR MOTION DRIVING SIMULATOR by Nicholas, T, Bolen

\author{
A Capstone Presented in Partial Fulfillment \\ of the Requirement for the Degree of \\ DOCTOR OF OCCUPATIONAL THERAPY \\ University of St. Augustine for Health Sciences
} April, 2020 
EXPLORING THE CONCURRENT VALIDITY OF THE INDOOR MOBILITY PREDRIVING SCREEN (IMPS): A COMPARISON OF THE IMPS AND EF-CAR MOTION DRIVING SIMULATOR

by

Nicholas, T, Bolen

has been approved

April, 2020

APPROVED:

Kayla Collins, EdD, OTR/L, Doctoral Coordinator

Thais Petrocelli, OTD, OTR/L, Doctoral Coordinator

Mary Shotwell, PhD, OT/L, Program Director

ACCEPTED AND SIGNED:

Kayla Collins $\frac{\text { Digitally signed by Kayla Collins }}{\text { Date: } 2020.07 .22100: 45: 14-0400^{\prime}}$

Kayla Collins, EdD, OTR/L, Doctoral Coordinator

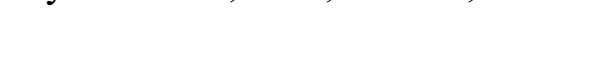

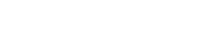

Thais Petrocelli, OTD, OTR/L, Doctoral Coordinator

Mary P. Shotwell, PhD, OT/L, $\quad \begin{aligned} & \text { Digitally signed by Mary P. Shotwell, PhD, OT/L, FAOTA } \\ & \text { DN: cr=Mary P. Shotwell, PhD, OT/L FAOTA, }=\text {-Unive-s }\end{aligned}$

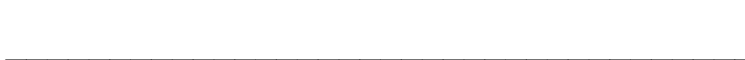

Mary Shotwell, PhD, OT/L, Program Director 
Table of Contents

Chapters

$\underline{\text { Pages }}$

1: Introduction. 6

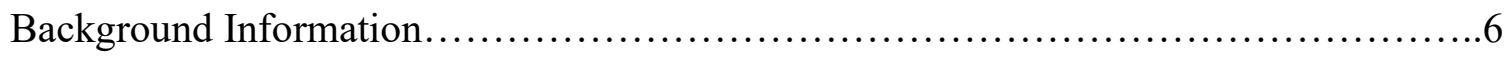

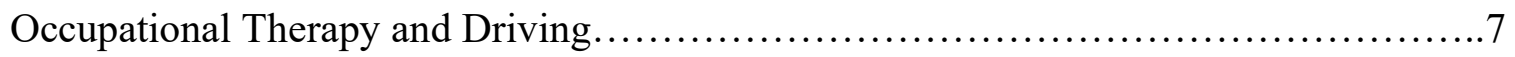

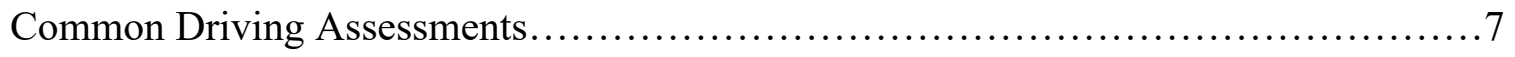

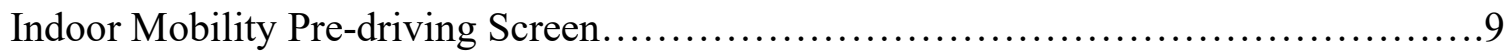

Problem Statement.......................................................................

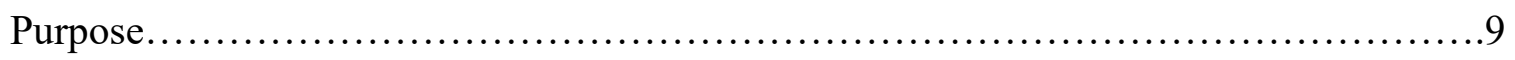

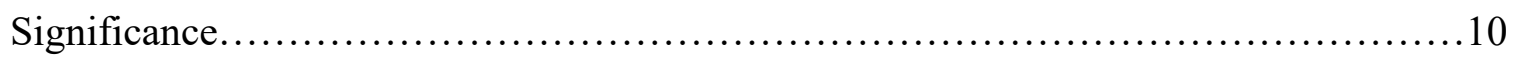

Theoretical Framework..........................................................10

Preliminary Project Objectives.................................................11

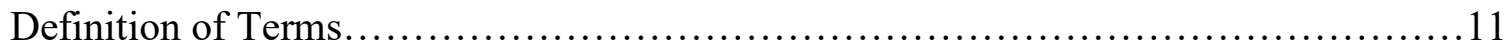

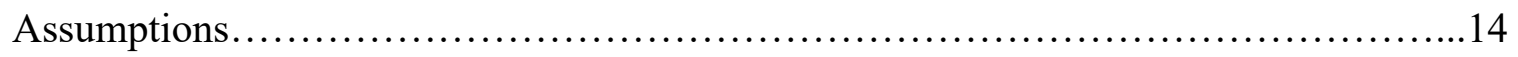

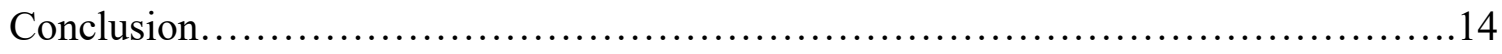

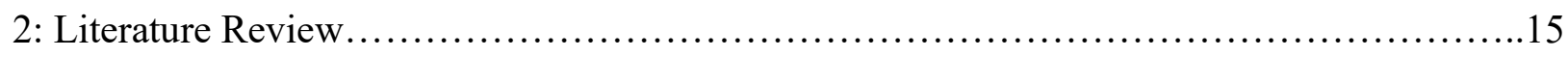

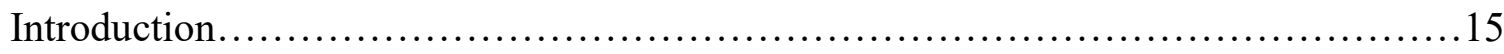

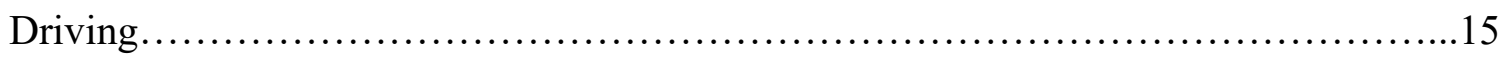


Skills Necessary for Safe Driving........................................... 17

Diagnoses Affecting Driving................................................ 19

Driver Rehabilitation......................................................... 21

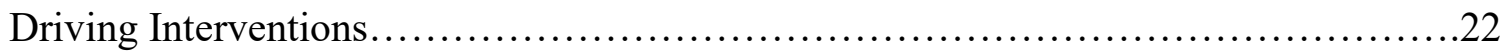

Driving Assessment.......................................................23

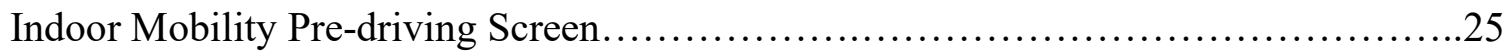

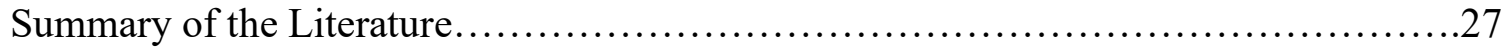

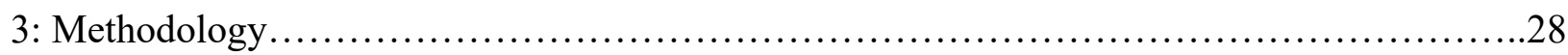

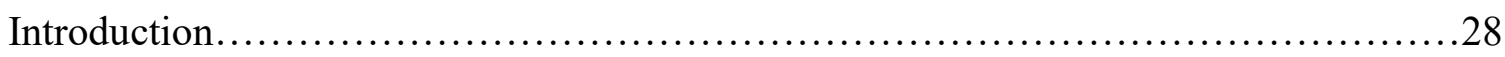

Research Question.....................................................29

Hypotheses............................................................. 29

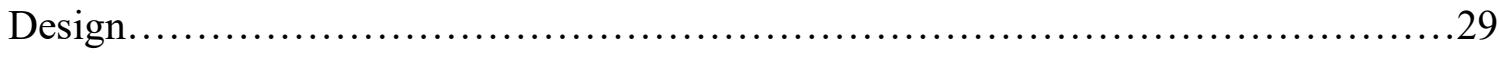

Participants...........................................................29

Recruitment...................................................... 30

Inclusion Criteria .................................................... 30

Exclusion Criteria................................................... 32

Assessments and Measures..................................................... 33

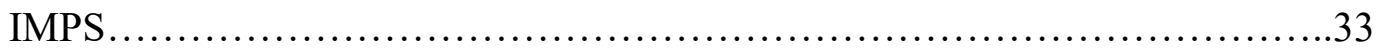


EF-Car Motion Driving Simulator....................................... 35

Procedures for Data Collection................................................. 36

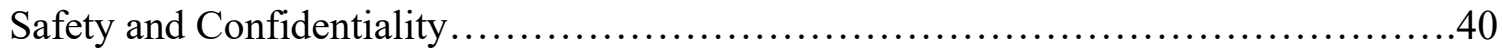

Data Analysis...........................................................42

Alignment with Project Objectives..........................................43

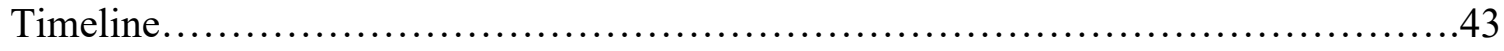

Summary of Methodology................................................44

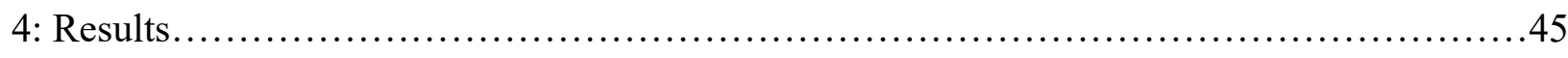

Introduction.......................................................... 45

Demographic Data..................................................... 45

Descriptive Statistics of Scores..........................................47

Results Related to the Primary Research Question..............................50

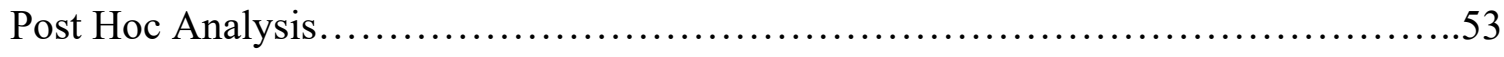

Limitations......................................................... 54

Delimitations...........................................................56

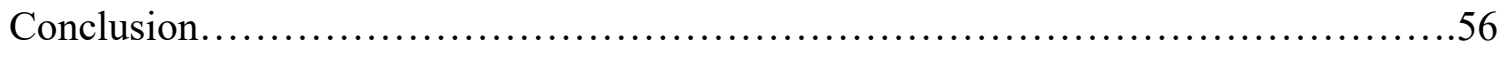

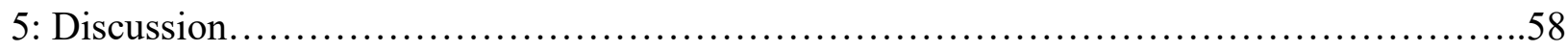

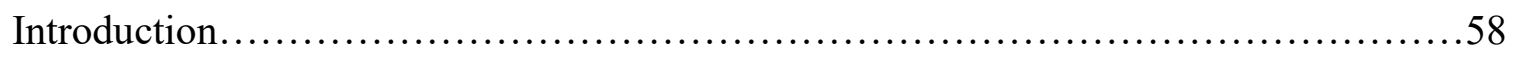




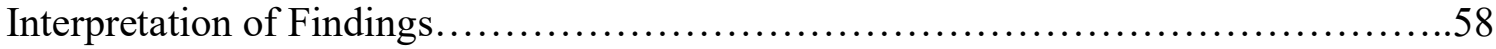

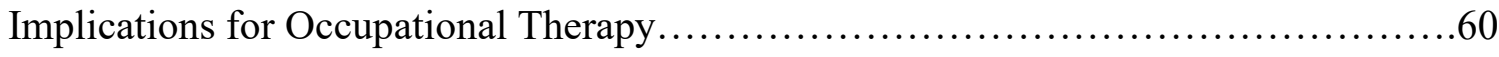

Implications for Future Research.............................................61

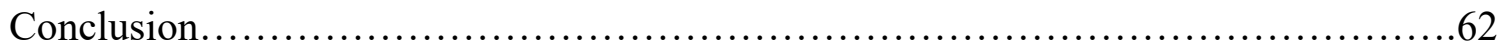

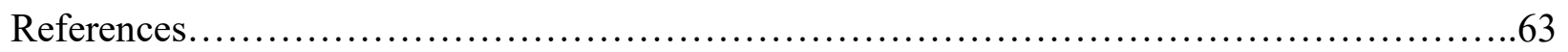




\section{Chapter 1: Introduction}

\section{Background Information}

Driving is a complex skill that millions of people in the United States rely on to engage in their daily activities. Driving is often an individual's primary source of transportation to access work, leisure activities, and the community (Bonnel, 1999). According to Bonnel (1999), these occupations include shopping, social outings, church attendance, and volunteer work. Crizzle et al. (2019), identified the cessation of driving is a difficult transition for individuals and their caregivers. Driving is often linked to feelings of independence and pride, particularly to those residing in the United States. Loss of the ability to drive limits community and social engagement and puts individuals at higher risk for feelings of loneliness and depression (Cooney, Curl, Proulx, \& Stowe, 2014). Additionally, housing and where an individual chooses to live are also affected by the ability to drive due to access or lack of access to public transportation in rural or suburban areas (Golisz, 2014).

According to the U.S. Department of Transportation, there were over 200 million licensed drivers in the United States alone (2017). On a national level, $84 \%$ of individuals of driving age are licensed to operate a motor vehicle (U.S. Department of Transportation, 2013). Information gathered by the U.S. Department of Transportation also found that drivers traveled over 13,000 miles a year, equal to over 35 miles a day (2018). An estimated 40,000 people died due to car accidents in 2018 (National Safety Council, 2018). With the number of drivers on the road increasing and millions of accidents occurring annually, ensuring safety on the road is critical for the well-being of our communities. 
Driving is a complex occupation requiring a plethora of performance skills in the areas of cognition, vision, and motor skills. Drivers must be able to process information and make quick, potentially life-altering decisions while driving. Cognitive skills involved in driving include memory, processing speed, decision making, attention and orientation (Boot, 2018). Visual skills necessary for driving include visual perception, visual-spatial, visual motor, and visual acuity (Niewoehner et al., 2012). Motor skills involved in driving include coordination, strength, range of motion, motor speed, and grip strength (Barco et al., 2014). Deficits in cognitive, visual, or motor skills can result in the inability to operate a motor vehicle safely. Individuals who have been diagnosed with a condition affecting cognition, vision, or motor skills are at a higher likelihood of being involved in a car accident (Niewoehner et al., 2012; Krasniuk et al., 2019).

\section{Occupational Therapy and Driving}

The AOTA has recognized the role of occupational therapists in driving assessment and driving intervention (AOTA, 2019). Driving is an important IADL listed in the Occupational Therapy Framework: $3^{\text {rd }}$ Edition (2014). Occupational therapists are holistic practitioners with the skills necessary to evaluate contextual factors, performance skills, and vehicle modification that may be required for an individual to operate a motor vehicle adequately and safely (Macdonald, Pellerito Jr., \& Di Stefano, 2006). Additional certifications and training on driving intervention and assessment are available through the AOTA and other organizations such as the Association for Driving Rehabilitation Specialists. Courses and examinations can be taken to these additional certifications and to enhance the knowledge and skills of the occupational therapy generalist.

\section{Common Driving Assessments}


There are many assessments available for use by occupational therapists to evaluate an individual's ability to drive. These assessments fall into two broad categories, in-clinic assessments and behind the wheel assessments. In-clinic assessments are those that can be performed indoors in a clinical setting while behind the wheel assessments are conducted while driving a vehicle. Dickerson (2013) identified 114 assessments used by driver rehabilitation specialists with some of the most common being: behind the wheel, vision testing, Trail Making Test parts A or B, physical assessment, brake reaction time, cognitive assessment, Short Blessed Test, and Useful Field of Vision. Other commonly used assessments for specific diagnoses are Clock Drawing Test, letter-number cancellation, Motor-Free Visual Perception Test (MVPT), convergence/divergence, ocular range of motion, Mini-Mental State Examination, saccades, sensation testing, Useful Field of View, and Draw a Person (Dickerson, 2013).

Driving simulators are becoming more common as a means of assessing an individual's capability to drive as an alternative to behind the wheel assessment. Currently, there is mixed evidence on the validity of driving simulators as a means of driving assessment (Wynne, Beanland, \& Salmon, 2019). There are many different driving simulators, each with their own programming, fidelity, and validity when it comes to assessing an individual's driving abilities. However, they are becoming more common despite their cost and lack of strong evidence supporting their use (Martin-DelosReyes et al., 2019; Wynne, Beanland, \& Salmon, 2019). However, the outlook on driving simulators in the future is hopeful. As technology advances, we can create scenarios that can more closely mimic those that occur organically while on the road.

Although there are many assessments to choose from when approaching driving assessment, there has yet to be one assessment or group of assessments, that is considered best able to accurately test and predict on the road outcomes across all populations (Dickerson, 2014). 
Current assessments are limited by being too specific, ineffective, impractical, or are too expensive.

\section{Indoor Mobility Pre-driving Screen}

The Indoor Mobility Pre-driving Screen (IMPS) was developed to be used as an in-clinic assessment to evaluate the skills needed for an individual to drive on the road safely. This assessment was born out of the ambiguity surrounding the selection of driving assessments and the need for one that can accurately assess pre-driving ability across a variety of diagnoses. The IMPS has value as an assessment to fill a void that exists in driving assessment if shown to be valid. The IMPS evaluates a person's vision while the individual is moving through the environment. This is known as dynamic vision, or vision when there is movement relative to the object perceived and the individual who is perceiving the object. Additionally, the IMPS assesses memory, wayfinding, and alternating attention, all while incorporating time into the score (Pope \& Tope, 2011). As a clinical assessment, the IMPS can consider a variety of performance skills commonly assessed by other pre-driver assessments simultaneously.

\section{Problem Statement}

Currently, there is no standardized in-clinic assessment for the evaluation of pre-driving skills (Dickerson, 2014). The IMPS has potential value as an in-clinic assessment due to being cost-effective while purporting to measure a multitude of performance skills needed for safe driving. The concurrent validity of the IMPS has been examined when compared to the Symbol Digit Modalities Test, Comprehensive Trail Making Test, Dynavision 2000, and the Posit Science Crash Risk Indicator in previous studies. The potential correlation between the IMPS and EF-Car Motion Driving Simulator has not yet been explored. 


\section{Purpose}

The purpose of this study was to compare and evaluate the scores of participants whose pre-driving skills have been assessed with both the IMPS and the EF-Car Motion Driving Simulator. Attempts will be made to explore any correlations in concurrent validity, which may or may not exist between the scores of these two assessments through statistical analysis.

\section{Significance}

The IMPS has been shown to be a valid tool for pre-driving assessment in initial studies (Pope \& Tope, 2011; Miles, Svay, Madrid, \& Crichton, 2014; Alhasmi, Hudson, MendezSchiaffino, \& Williford, 2016). Continued research needs to be conducted to establish its efficacy as a pre-driving screen. Similarly, driving simulators are relatively new in the realm of pre-driving assessment. A comparison study of these two assessments will further the body of knowledge that exists on driving simulators. If the IMPS is proven to be a valid assessment, it provides the opportunity to change how pre-driving skills are assessed, potentially resulting in decreasing the number of unsafe drivers on the road. A decrease in dangerous drivers could lead to a reduction in traffic deaths and accidents. Conversely, validation of the IMPS as a standardized in-clinic assessment would provide a new screening tool that can easily be learned and implemented by both the occupational therapy generalist and specialist. Access to a valid clinical assessment tool could potentially allow for safe drivers to return to the road, and ultimately regain their lost independence and occupational engagement.

\section{Theoretical Framework}

For this study, Michon's Hierarchy of Driving Behavior was considered to understand the components of the IMPS and driving simulator. Michon, in this framework, describes driving in 
three distinct levels. The first, "strategic level" involves higher-level decision making to determine the goals of the trip, means of transportation, and navigation to the destination. The second "tactical level" involves decisions made during driving maneuvers such as taking turns, passing other motorists, etc. The third and final level is the "operational level." The operational level involves decisions made to control the vehicle safely through the use of necessary visualmotor and coordination skills (Patomella, Kottorp, \& Tham, 2008). This framework comprehensively addresses the higher-level cognitive requirements of driving as well as the physical skills needed.

\section{Preliminary Project Objectives}

- Analyze and discuss the results of participants' data whose pre-driving skills have been assessed with the IMPS and the EF-Car Motion Driving Simulator.

- Explore concurrent validity of the IMPS when compared to the EF-Car Motion Driving Simulator.

- Develop a presentation to disseminate the results of data analysis and concurrent validity studies.

- Create an original manuscript draft to document the results of the research studies in conjunction with the project mentor.

\section{Definition of Terms}

Occupational Therapy (OT). Occupational therapy, as defined by the AOTA in the Occupational Therapy Practice Framework $3^{\text {rd }}$ Edition, is “the therapeutic use of everyday life activities (occupations) with individuals or groups for the purpose of enhancing or enabling participation in roles, habits, and routines in home, school, workplace, community, and other settings" (2014). 
Occupations. Occupations consist of every day, meaningful life activities. There are eight main areas of occupation: activities of daily living (ADLs), instrumental activities of daily living (IADLs), rest and sleep, education, work, play, leisure, and social participation (AOTA, 2014). These include activities that individuals want to do, need to do, and are expected to do. Activities of Daily Living (ADLs). A group of activities focused on the care of one's body. ADLs, sometimes referred to as basic activities of daily living (BADLs), include bathing, toileting, dressing, eating, feeding, functional mobility, personal device care, hygiene and grooming, and sexual activity (AOTA, 2014).

Instrumental Activities of Daily Living (IADLs). A group of activities, often more complex than ADLs, which support daily life both in the community and at home (AOTA, 2014). Examples of IADLs include childcare, driving and community mobility, financial management, and pet care (AOTA, 2014).

Driving Simulator. This term, concerning this study, will refer specifically to the EF-Car Motion Driving Simulator. The lexicon, "driving simulators," refers to any driving simulator created by any number of companies and is not specific to the EF-Car Motion Driving Simulator. A driving simulator is a device consisting of a seat with a monitor or monitors facing the front of the seat. All controls that are present in a vehicle are present in the driving simulator, such as a seat belt, throttle, brake, clutch, gear shift, turn signals, and windshield wipers.

Community Mobility. Community mobility is the process of, "Planning and moving around in the community and using public or private transportation such as driving, walking, bicycling, or accessing and riding buses, taxi cabs, or other transportation systems" (AOTA, 2014) 
Motor Skills. This term refers to the physical attributes of a person related to muscle strength, muscle coordination, and muscle endurance. Deficits in this area can result in dysfunction of one's control of their movements.

Dynamic Vision. Dynamic vision refers to one's ability to see an object while there is motion between the object and the individual perceiving the object.

Visual Perception. Visual perception refers to one's ability to receive, process, and understand visual stimuli in their environment.

Acquired Brain Injury (ABI). Acquired brain injuries are injuries to the head and brain that an individual is not born with but rather acquires during their lifespan. These injuries can result in numerous cognitive and physical deficits. This term is often used interchangeably with traumatic brain injuries (Powell, 2013).

Traumatic Brain Injury (TBI). A condition in which the brain is injured through trauma of any sort to the head. These injuries can be open or closed and can result in numerous cognitive and physical deficits (Powell, 2013).

Cerebrovascular Accident (CVA). Cerebrovascular accidents often referred to as strokes, are caused when oxygen supply to the brain is cut off secondary to blockage or rupture of a brain dwelling blood vessel. Depending on the site of the lesion, numerous physical and cognitive deficits can result (Woodson, 2013).

Useful Field of View (UFOV). Useful Field of View is the name of an assessment that measures one's ability to perceive, analyze, and respond to sensory input (Radomski \& Giles, 2013). When not referencing this specific test, useful field of view refers to the total area of the visual field in 
which useful information can be received with no head or eye movement (O'Shea \& Woods, 2018).

\section{Assumptions}

This capstone project assumes that the EF-Car Motion Simulator will be available for use and will not have any major technical malfunctions during the study. It is also assumed that the sample size of participants will be generalizable to the overall population. This study assumes that all individuals who participate in the study will participate to the extent of completing all procedures.

\section{Conclusion}

Driving is an important IADL that provides individuals with access to their communities and the many different occupational opportunities contained within. Occupational therapists play an important role in driving assessment and rehabilitation. Occupational therapists have many tools to choose from when performing a driving assessment. However, according to current literature, no one driving assessment or group of assessments has been determined to accurately predict on the road driving outcomes (Dickerson, 2014). This gap will be further explored in the following section of this paper. 


\section{Chapter 2: Literature Review}

\section{Introduction}

This section contains literature reviewed that is relevant to the current study, including articles addressing driving, driver rehabilitation, and driving assessment from the following disciplines: occupational therapy, gerontology, and medicine. Literature was gathered in reviewed utilizing the following databases and resources: American Journal of Occupational Therapy, Journal of Psychiatric Research, CINAHL complete, EBSCO Host, Taylor \& Francis Online, Health and Medical Collection, DAOJ, Science Direct, and Gale Academic Onefile. Search terms utilized include the following: occupational therapy, driving, driver rehabilitation, driving assessment, vision, driving simulator, driving intervention, driving rehabilitation specialist (DRS), certified driving rehabilitation specialist (CDRS), community mobility, dynamic vision, and lifespan. The objective of this literature review is to explore driving and the many facets related to it. While many diagnoses impact driving in various ways, these will not be explored in their entirety. Instead, a brief overview of how these conditions can affect driving secondary to deficits in performance skills will be included in this review. Topics in this review include: driving, driving assessment, driving rehabilitation, IMPS (formerly TYDAV), and certified driving rehabilitation specialists.

\section{Driving}

Driving is a complex instrumental activity of daily living (IADL) that is viewed by many as a primary source of independence and access to many other occupations (American Occupational Therapy Association [AOTA], 2014). Driving provides a source for individuals to access and navigate their community for engagement in other occupations, more commonly 
referred to as community mobility (Bonnel, 1999). Community mobility is defined by the AOTA as "planning and moving around in the community and using public or private transportation, such as driving, walking, bicycling, or accessing and riding in buses, taxi cabs, or other transportation systems" (2014, p. S19). Transportation from one location to another allows access for people to do the things they want to do. For example, grocery shopping, social participation, education, work, leisure, and many other occupations require a means of transit from one location to another (Bonnel, 1999). According to the AOTA (2017), "community mobility is grounded in independence, spontaneity, and identity. It begins when we are passengers in a car seat and on the school bus, and continues as we learn to ride a bike and drive a car."

According to the U.S. Department of Transportation (2017), there were over 200 million licensed drivers in the United States alone. On a national level, $84 \%$ of individuals of driving age are licensed to operate a motor vehicle (United States Department of Transportation, 2013). Information gathered by the U.S. Department of Transportation also found that drivers traveled over 13,000 miles a year or over 35 miles a day (2018). According to Driver Knowledge (2017), over six million car accidents occur annually in the United States, with over three million drivers sustaining injuries. Out of those three million injured, two million sustain permanent injuries (Driver Knowledge, 2017). An estimated 40,000 people died due to car accidents in 2018 (National Safety Council, 2018). With the number of drivers on the road increasing each year and millions of accidents, ensuring safety on the road is critical.

Drivers with disabilities may be at higher risk for car accidents and car accident-related injury due to functional limitations secondary to conditions such as stroke, dementia, acquired brain injury, ADHD, ASD, other developmental disabilities, and acquired physical disabilities 
(Bishop, Stavrinos, Boe, \& Mirman, 2018; Eby, Molnar, \& Pellerito, 2006; Stressel, Hegberg, \& Dickerson, 2014). Due to the higher risk for driving problems, drivers with disabilities often need to be assessed to ensure they can safely operate a vehicle on the road. Occupational therapists often conduct comprehensive driving evaluations in addition to DRSs and certified driver rehabilitation specialists CDRSs. According to Dickerson (2013), both generalist occupational therapists and DRS/CDRSs have the skills necessary to conduct a comprehensive in-clinic pre-driving assessment as well as behind-the-wheel assessment. There are a variety of evaluation tools available for clinicians to use in the assessment of driving skills. However, one assessment or group of assessments has not yet emerged as the most reliable, quick, and useful tool for the evaluation of pre-driving skills (Dickerson, 2014).

\section{Skills Necessary for Safe Driving}

Driving is a complicated occupation requiring a plethora of performance skills in the areas of cognition, vision, sensory functions, and motor skills (Dickerson, 2013). Drivers must be able to process information and make quick, potentially life-altering decisions while driving. Therefore, client factors are essential for driving safely. AOTA (2017) states, "Cognition refers to information-processing functions, including attention, memory, and executive functions (i.e., planning, problem-solving, self-monitoring, self-awareness).” Cognitive skills involved in driving include memory, processing speed, decision making, executive functioning, attention, and orientation (Boot, 2018; Carr \& Ott, 2010; Stapleton, Connolly, \& O’Neill, 2015). Visual skills necessary for driving include visual perception, visual-spatial, visual motor, and visual acuity (Niewoehner et al., 2012). Motor skills involved in driving include hand-eye coordination, strength, range of motion, motor speed, and grip strength (Dickerson, 2013). Sensory factors also contribute to one's ability to drive safely. Dysfunction in proprioception, peripheral sensation, 
spatial awareness of vehicle controls, balance, and postural positioning can lead to the inability to drive safely (Lacherez, Wood, Anstey, \& Lord, 2014). Deficits in cognitive, visual, or motor skills can result in the inability to operate a motor vehicle safely. Individuals diagnosed with a condition affecting cognition, vision, or motor skills are at a higher likelihood of being involved in a car accident (Niewoehner et al., 2012; Krasniuk et al., 2019; Lacherez, Wood, Anstey, \&

Lord, 2014; Stolwyk et al., 2019).

\section{Table 1}

Client Factors and Their Relation to Driving

\begin{tabular}{|c|c|c|}
\hline Client factors & Specific skills & $\begin{array}{l}\text { Why are they needed for } \\
\text { driving? }\end{array}$ \\
\hline Cognition & $\begin{array}{l}\text { - } \text { Executive functioning } \\
\text { - } \text { Memory } \\
\text { - Processing } \\
\text { - } \text { Emotional regulation } \\
\text { - } \text { Consciousness } \\
\text { - Attention } \\
\text { - Orientation }\end{array}$ & $\begin{array}{l}\text { Driving requires strict focus and } \\
\text { the ability to filter out non- } \\
\text { essential information. Cognition } \\
\text { is important for processing } \\
\text { environmental stimuli, } \\
\text { remembering the meaning of } \\
\text { signs and signals, multitasking, } \\
\text { anticipating other drivers' } \\
\text { actions, reacting to } \\
\text { unanticipated events. }\end{array}$ \\
\hline Vision & $\begin{array}{ll}\text { - } & \text { Visual acuity } \\
\text { - } & \text { Visual fields } \\
\text { - } & \text { Visual scanning } \\
\text { - } & \text { Visual-spatial } \\
\text { - } & \text { Visual discrimination } \\
\text { - } & \text { Convergence } \\
\text { - } & \text { Divergence } \\
\text { - } & \text { Accommodation }\end{array}$ & $\begin{array}{l}\text { Visual skills are needed for } \\
\text { observing the environment, } \\
\text { identifying cars, objects, or } \\
\text { people within one's field of } \\
\text { view (FOV), and reading traffic } \\
\text { signs/signals. }\end{array}$ \\
\hline Motor skills & $\begin{array}{ll}\text { - } & \text { Strength } \\
\text { - } & \text { Endurance } \\
\text { - } & \text { Tone } \\
\text { - } & \text { Range of motion } \\
\text { - } & \text { Postural control } \\
\text { - } & \text { Motor reflexes } \\
\text { - } & \text { Motor coordination }\end{array}$ & $\begin{array}{l}\text { Motor skills are needed for the } \\
\text { user to interface with the motor } \\
\text { vehicle by operating } \\
\text { components such as the steering } \\
\text { wheel, throttle, brakes, turn } \\
\text { signals, etc. They are also } \\
\text { needed so the individual can } \\
\text { fully scan their environment by } \\
\text { turning their head. }\end{array}$ \\
\hline Sensory functions & $\begin{array}{ll}\text { - } & \text { Auditory functions } \\
\text { - } & \text { Vestibular functions } \\
\text { - } & \text { Proprioception } \\
\end{array}$ & $\begin{array}{l}\text { Sensory functions are needed for } \\
\text { receiving audible cues from the } \\
\text { operated vehicle, other vehicles, }\end{array}$ \\
\hline
\end{tabular}


- Touch

- Sensitivity to pressure and sounds in the environment. Sensation is also needed for safe operation of vehicle controls, such as applying appropriate pressure on the brakes/throttle.

\section{Diagnoses Affecting Driving}

Many diagnoses may impact an individual's ability to drive safely — especially those which affect an individual's cognition. A systematic review conducted by Hird, Egeto, Fischer, Naglie, and Schweizer (2016) identified that individuals with Alzheimer's disease and individuals with mild cognitive impairment are often unsafe to drive secondary to reduced client factors needed for driving. In the review conducted by Bishop, Boe, Stavrinos, and Mirman (2018), identified several factors related to unsafe driving in individuals with ASD and ADHD. Aduen, Kofler, Cox, Sarver, and Lunsford (2015) also found that individuals with ADHD are at higher risk for collisions and at-fault accidents.

Individuals diagnosed with conditions affecting vision are also prone to being unsafe drivers. Bhorade et al., (2016) found that individuals with bilateral moderate and advanced glaucoma received significantly lower scores on Trail making Tests A and B, Rapid Pace Walk, Braking Response Time, and identifying traffic signs than individuals without glaucoma. These assessments are commonly used by OTs to predict a driver's on the road driving abilities (Dickerson, 2013). In a 2004 study by Szylk et al., the driving performance of diabetic retinopathy patients was assessed using an interactive driving simulator and a driving history questionnaire. Results showed a significant correlation between increased retinal thickness and a higher frequency of simulator accidents, near accidents, steeper brake-response slopes, increased brake-pressure standard deviation, and longer braking response times (Szylk et al., 2004) 
Individuals who have suffered a cerebrovascular accident (CVA), more commonly referred to as a stroke, are also at higher risk for unsafe driving (Stapleton, Connolly, \& O’Neill, 2015; Unsworth et al., 2019). According to the American Stroke Association (n.d.) CVAs are the fifth leading cause of death and the number one leading cause of disability in the United States. CVAs can result in a variety of symptoms affecting cognition, visual perception, range of motion, emotional regulation, sensation, muscle tone, and muscle strength (Mayo Clinic, n.d.). These symptoms vary depending on where the stroke occurred within the brain. Devos et al. found a significant correlation between the site of lesion and driving performance following an ischemic stroke (2015). Results showed strokes affecting the lobes of the brain, which control visual-perception and cognition had the largest effect on an individual's ability to drive safely.

Individuals with acquired physical disabilities such as COPD are also at risk for unsafe driving (Stressel, Hegberg, \& Dickerson, 2014). Hasan et al. (2015) explored the effect of shoulder immobilization on driving performance. They found that immobilization of the dominant driving arm resulted in decreased driving performance and safety. This data is not specific to any diagnosis but rather a potential symptom of many diagnoses which can affect the shoulder; thus, demonstrating how driving safety can be affected by physical limitations.

In addition to the diagnoses discussed above, many other conditions affect the performance skills necessary for safe driving. According to the Centers for Disease Control and Prevention (CDC) (n.d.), there are 61 million adults in the U.S. living with disabilities. Out of the total population in the U.S., $10.8 \%$ live with a disability affecting cognition, $4.6 \%$ live with a disability affecting vision, $6.8 \%$ live with a disability affecting independent living, and 13.7\% live with a disability affecting mobility (Centers for Disease Control and Prevention, n.d.). Drivers with disabilities often require evaluation and rehabilitation to drive safely due to having 
an increased likelihood of being involved in motor vehicle accidents (Niewoehner et al., 2012;

Krasniuk et al., 2019).

\section{Driver Rehabilitation}

Many drivers with disabilities receive driver assessment and rehabilitation services to improve driving safety and to regain independence with occupations through accessing their community (Driving and community mobility, 2010). The driver rehabilitation process starts with a comprehensive assessment of the individual, followed by the determination of the need for rehabilitative services. Driving assessments fit into two broad categories, behind-the-wheel evaluation and in-clinic evaluation (Dickerson, 2013; American Occupational Therapy Association [AOTA], 2017; Dickerson, 2014). If the assessing clinician determines the need for further services, client-centered driving interventions and training with adaptive equipment or vehicle modification will follow (Green, 2019).

Driver rehabilitation services are often a collaborative effort by multiple disciplines composed of professionals with different qualifications and certifications. Primary members of the driving rehabilitation team are occupational therapists, driver rehabilitation specialists, and certified driving rehabilitation specialists (Dickerson, 2013). Other disciplines are involved in the care of clients receiving driver rehabilitation services (Dattoma, 2017). A distinction must be made between DRSs, CDRSs, and driving instructors. The Association for Driver Rehabilitation Specialists explains that the CDRS certification is the gold-standard credential offered by their association and can be obtained through formal certification examination (Association for Driver Rehabilitation Specialists, n.d.). DRSs are still considered professionals within the driving rehabilitation realm. However, despite specializing in and received continuing education in this area of practice, DRSs have not passed the formal examination to receive certification 
(Association for Driver Rehabilitation Specialists, n.d.). Driving instructors are individuals who have received certification in their respective states to teach people how to drive (Dickerson \& Davis, 2012).

Occupational therapists are skilled rehabilitation specialists with the training and knowledge to evaluate the many different client factors needed for driving (Macdonald, Pellerito Jr., \& Di Stefano, 2006). Driving is an important IADL and is a primary means for community mobility as established in the Occupational Therapy Practice Framework: Domain and Process, $3^{\text {rd }}$ Edition (American Occupational Therapy Association [AOTA], 2014). Occupational therapy practitioners can holistically identify and address the needs of their clients in a variety of settings and for a variety of occupations, including driving (Driving and community mobility, 2010). Occupational therapists specializing in driving rehabilitation can earn CDRS certification, and many of them do. Additional certification allows for occupational therapists to better assess and address client factors, context, and the individual's driving environment. Furthermore, occupational therapists possess an understanding of how various medical diagnoses and impairments can affect the skills needed for driving (Stav, 2015).

\section{Driving Interventions}

Following the completion of a comprehensive driving evaluation, a personalized intervention plan is developed by the driver rehabilitation team to address the needs of the client (Stav, 2015). Driving interventions occur in many different forms and address multiple performance skills areas and client factors. However, most intervention approaches fall into five main categories: education, cognitive and perceptual, physical exercise, simulator training, and on-road training (Stav, 2015). Educational interventions focus on teaching individuals the rules of the road, sign recognition, and instruction on adaptive equipment. Interventions addressing 
cognitive-perceptual skills may include video-based perception training to recognize hazards or dangerous driving situations. The many facets of cognition can be addressed using meaningful activities to increase processing speed, decision making, and executive functioning. Physical fitness programs can be used to increase strength, range of motion, and endurance needed for the physical aspects of driving, such as postural control (Golisz, 2014). Intervention methods utilizing driving simulators are becoming increasingly common, and research on their validity is being done. There is currently mixed evidence with many studies finding their effectiveness inconclusive, while others show positive results in individuals who received training on a driving simulator (Martin-delosReyes et al., 2018; Unsworth \& Baker, 2014; Wynne, Beanland, \& Salmon, 2019).

\section{Driving Assessment}

Comprehensive driving assessments can be completed by driving rehabilitation specialists (DRSs) or occupational therapists (Wheatley, Pellerito, \& Redepenning, 2006). Predriver assessment and driving assessment predominantly occur in-clinic or behind the wheel (Vrkljan, McGrath, \& Letts, 2011). Clinical occupational therapy evaluation for driver assessment includes evaluation of performance skills needed for driving such as visual acuity, visuomotor skills, range of motion, sensation, strength, and cognition. The occupational therapist develops a profile highlighting the client's strengths and weaknesses related to driving and then develops a personalized, client-centered plan for intervention (Green, 2019). Despite the existence of many clinical assessment tools, the gold standard of driver assessment is behind the wheel assessment (Dickerson, 2013). However, this is not always a feasible option due to safety, time, and required certified personnel (Dickerson, 2013). 
There are many assessments available for use by occupational therapists to evaluate an individual's ability to drive. These assessments fall into two broad categories, in-clinic assessments and behind the wheel assessments. In-clinic assessments are those that can be performed indoors in a clinical setting while behind the wheel assessments are conducted while driving a vehicle. Dickerson (2013) identified 114 assessments used by driver rehabilitation specialists with some of the most common being: Behind the wheel, vision testing, Trail Making Test parts A or B, physical assessment, brake reaction, cognitive assessment, Short Blessed Test, and Useful Field of Vision. Other commonly used assessments for specific diagnoses are: Clock Drawing Test, letter-number cancellation, Motor-Free Visual perception Test (MVPT), convergence/divergence, ocular range of motion, Mini-Mental State Examination, Trail Making Test, saccades, Short Blessed Test, Sensation, Useful Field of View, and Draw a Person (Dickerson, 2013).

While it may seem as though having access to a large number of assessments is a good thing when approaching driving assessment, it is a limitation. Dickerson (2013) identified 114 assessments, many of which only measure specific skills, while others overlap and purport to measure the same skills. Yet, there is still no consensus upon the existence of one assessment or group of assessments, which best measures skills needed for driving. The examination of this study directly points to the need for validation of a standardized in-clinic tool for assessing driving readiness.

Driving simulators are becoming more common as a means of assessing an individual's capability to drive as an alternative to behind the wheel assessment. Lew et al. found that simulator-based assessment of patients with brain injuries can provide ecologically valid measures (2005). Meuleners and Fraser (2015) concluded their preliminary results provide 
support for the relative validity of the driving simulator. Ultimately though, there is mixed evidence on the validity of driving simulators as a means of driving assessment (Wynne, Beanland, \& Salmon, 2019). There are many different driving simulators, each with distinct programming, fidelity, and validity when testing the many facets crucial to safe driving. Despite this fact, they are becoming more common despite their cost and lack of evidence supporting their use (Martin-Delos Reyes et al., 2019; Wynne, Beanland, \& Salmon, 2019). However, the outlook on driving simulators in the future is bright. As technology advances, we can create scenarios that can more closely mimic real-life situations. Driver simulators can provide a safer, more controlled alternative to BTW assessments (Dickerson, 2014). These simulators can also record errors, measure outcomes, and provide a just-right challenge for the individual.

Although there are many assessments to choose from when approaching driving assessment, there has yet to be one assessment or group of assessments, that is considered able to accurately test and predict on the road outcomes across all populations (Dickerson, 2014). Current assessments are limited by being too specific, ineffective, impractical, or expensive. In this study, attempts will be made to validate the IMPS further to provide access to an assessment needed by practitioners to quickly and effectively measure a client's pre-driving skills.

\section{Indoor Mobility Pre-driving Screen}

The Indoor Mobility Pre-Driving Screen (IMPS), formally known as the Tracey Young Dynamic Assessment of Vision (TYDAV), was created by Tracey Young to fill the need for a clinical-based pre-driver assessment of vision. The IMPS purports to measure components of an individual's cognitive, physical, and visual functions needed for driving. The IMPS consists of a timed test in which the participant finds their way to a specific location and back to the start. During the assessment, the individual must attend to visual cues and efficiently navigate to the 
designated location. The IMPS assesses eight domains, including memory, attention, problemsolving, mobility, visual scanning at midline, scanning of the right visual field, scanning of the left visual field, acting on informational signs, wayfinding, and accuracy (Pope \& Tope, 2011).

Several studies have been conducted on the IMPS, thus far exploring the validity of the IMPS when compared to other assessments. Pope and Tope (2011) found there is a statistically significant relationship between the TYDAV and Symbol Digit Modalities Test (SDMT). They also explored the potential correlation between the TYDAV and the Posit Science Crash Risk Evaluator and the Comprehensive Trail Making Test (CTMT). No correlations were found between the TYDAV and these two assessments. Miles, Svay, Madrid, \& Crichton (2014) found significant correlations between the TYDAV and the Dynavision 2000, a tool used to assess useful field of vision (UFOV). Alhashmi, Hudson, Mendez-Schiaffino, \& Williford (2016) explored known groups validity of the TYDAV when investigating potential differences between individuals with and without acquired brain injuries (ABI). They found significant differences in TYDAV scores between individuals with and without ABI. The researchers also discovered a significant correlation in TYDAV total scores and Dynavision 2000 average speeds in all trials except one. Amos, McKown, \& Wilson, (2012) explored concurrent validity between the TYDAV and the SDMT, CTMT, and the Posit Science Crash Risk Evaluator in individuals with $\mathrm{ABI}$ and found no significant correlations. Concurrent validity has yet to be established or explored between the IMPS and a driving simulator.

In this study, attempts will be made to explore concurrent validity between the IMPS and the E.F. Car Motion Driving Simulator to determine if there is a correlation between scores on these tools. The driving simulator was selected as a comparison measure due to its rise as a more feasible alternative to a BTW assessment and to further the body of knowledge on the method of 
assessment and intervention. Unfortunately, there is no information that considers the validity or predictability of the EF-Car Motion Driving Simulator available in the literature. The current consensus of literature available on driving simulators regarding their validity is mixed with some studies finding them reliable and others finding inconclusive results (Justiss, 2013; Hird et al., 2016; Unsworth \& Baker, 2014; Schreier, Banks, \& Mathis, 2018; Kaye, Lewis, \& Freeman, 2018).

\section{Summary of the Literature}

Driving is an important IADL which provides many individuals with access to their communities for engagement in work, socialization, education, and leisure activities. The role of occupational therapy in driving assessment and rehabilitation is well-identified within the scope of the practice (AOTA, 2014). There is a multitude of assessments available to clinicians to implement into practice (Dickerson, 2013). However, these options are limited when addressing the complex occupation of driving. Also, the determination of one assessment best able to evaluate the skills needed for driving has not occurred (Gamache, Hudon, Teasdale, \& Simoneau, 2010). There is a real need for a standardized in-clinic assessment that can be easily implemented into practice by the occupational therapy generalist and specialist alike. 


\section{Chapter 3: Methodology}

\section{Introduction}

The purpose of this study was to establish and explore the concurrent validity between the Indoor Mobility Pre-driving Screen (IMPS) in relation to constructs measured by the EF-Car Motion Driving Simulator. The IMPS has the potential to be a valuable tool for the evaluation of dynamic vision and pre-driving skills as it measures skills in many domains of individual function necessary for safe driving. Currently, literature does not support one assessment or group of assessments that best predict the outcome of on the road driving assessment (Dickerson, 2013). The IMPS can potentially fill this void if proven a valid and predictable measure. However, comprehensive validation of the IMPS needs to be further explored before the IMPS can fulfill the identified gap in the literature. Some efforts to validate the IMPS have been done in four previous studies to date (Pope \& Tope, 2011; Amos, McKown, \& Wilson, 2012; Pascal, 2013; Miles, Svay, Madrid, \& Crichton, 2014). This study is seeking to add to the body of knowledge by further exploring the concurrent validity of the IMPS as a pre-driving screening tool. Constructs measured by the IMPS were compared with five rehabilitation programs on the EF-Car Motion Driving Simulator by Simulator Systems International. The five programs are as follows: a) reaction time, b) cognitive abilities, c) field of view, d) glare/memorization, and e) situational awareness.

Attempts were made to establish and explore the concurrent validity between the IMPS and the EF-Car Motion Driving simulator during this study. Portney and Watkins (2015) describe concurrent validity as the degree to which the outcomes of one assessment correlate with the outcomes of a criterion assessment. Furthermore, Portney and Watkins (2015) state, "concurrent validity is studied when the measurement to be validated, and the criterion measure 
are taken at relatively the same time (concurrently) so that they both reflect the same incident of behavior" (p. 103). This was the first study done exploring the concurrent validity of the IMPS in comparison to a driving simulator.

\section{Research Question}

Establishing concurrent validity, as discussed above, requires the comparison of two tests, one of which is the criterion measure. Therefore, the research question posed in this study is as follows: Is there a correlation between scores on the IMPS and the EF-Car Motion Driving Simulator?

\section{Hypotheses}

As this is a nonexperimental design, a hypothesis is not necessarily appropriate, though the researcher is assuming that there is a correlation between the scores of the IMPS and the EFCar Motion Driving Simulator in individuals ages 18 and up who currently possess a valid driver's license.

\section{Design}

The design of this study was a nonexperimental assessment comparison study of concurrent validity. Despite being of nonexperimental design, the order of assessment administration was randomized to prevent the introduction of bias through the form of carryover and testing effects into the study (Portney \& Watkins, 2015).

\section{Participants}

A convenience sample of 36 community-dwelling individuals ( 22 females \& 12 males) were recruited from St. Johns county and the surrounding areas. A convenience sample consists 
of subjects chosen based on availability (Portney \& Watkins, 2015). This method of participant recruitment was utilized for the sake of convenience and the availability of potential participants across the desired age range (18 and up) that were within proximity to the research location. Additionally, attempts were made to stratify the participant sample into increments of 10 years (e.g., 20-29, 30-39, 40-49, etc.) to prevent the entire sample from consisting of individuals of similar ages.

\section{Recruitment.}

After receiving approval from the USAHS institutional review board (IRB), the researchers began recruiting participants for the study. Faculty members at USAHS, including the principal investigator, assisted with recruitment through word of mouth via their personal and professional networks. A flyer was created and disseminated within the community (USAHS, USAHS pro-bono clinic, and two local rehabilitation facilities) by the investigators with faculty assistance. Additionally, several individuals who participated in the study contacted family and friends they believed may be interested in participating. Several individuals who participated in the study heard about the opportunity for participation from a friend or family member who had recently participated. After hearing about the study from one of the various methods above, interested participants reached out to the investigators in person, via phone, or via email and expressed interest in participating. Before participating in the study, each interested individual was screened over phone, email, or in-person to ensure they met the inclusion criteria of the study. Individuals who met the inclusion criteria were then scheduled for a one-hour session at the USAHS campus in St. Augustine, Florida, to participate in the study.

\section{Inclusion Criteria.}


Several inclusion criteria were present in this study to ensure an appropriate sample of participants was gathered. Each participant was at least 18 years old and had a valid driver's license. The decision was made to exclude individuals of driving age below the age of 18 (e.g., 15-17) for two reasons. The first was for the sake of convenience as the inclusion of minors adds additional procedures for participation, such as having a legal guardian present to sign the informed consent waiver. The second reason why individuals of this age range were excluded is it was presumed that individuals ages 18 and older have more driving experience than younger drivers. Individuals who seek comprehensive driving assessment and ultimately driving rehabilitation are individuals who have experience as active drivers. Therefore, a sample of participants of this age range more closely matches the overall population of people seeking driving assessment and rehabilitation.

All participants were also required to be able to engage in a session lasting approximately 60 minutes in which the participant completed an informed consent waiver, a demographic form, and both assessments. To truly explore the concurrent validity of the IMPS in comparison to the driving simulator, both assessments had to be taken at relatively the same time (Portney \& Watkins, 2015). While none of the procedures were considered physically demanding, participants did need the stamina required to complete all study procedures during a single one10hour session.

To be included in this study, participants had to engage in functional mobility, with the use of ambulatory assistive devices if needed, for 125-175 feet for completion of the IMPS. The IMPS is not a measure that requires a high level of physical endurance or strength; however, it does require a certain level of physical ability for completion. Time is a component of scoring for this assessment, but participants were instructed to maintain a safe, comfortable pace. 
Participants in the study were required to be able to speak and understand English for the understanding of novel, multi-step (3-4) assessment instructions, and to communicate the need to withdraw from the study if they desired. The exclusion of individuals who did not speak English was necessary to prevent biased test results, maintain the safety of each participant, and for respecting participants' right to withdraw at any point.

\section{Exclusion Criteria.}

If a participant did not meet the above criteria or met any of the following criteria, he or she was not included in the study. Individuals with knowledge of having acute medical conditions that would prohibit them from taking the assessments (e.g., severe bacterial or viral infection, acute traumatic injury, acute spinal cord injury) were excluded from the study. It would have been neither safe nor appropriate to have participants with acute medical conditions to take part in the study for both safety and liability reasons.

While individuals with mild cognitive impairment were included in the study, those with significant cognitive impairment were excluded. Some examples of what was considered significant cognitive impairment include severe traumatic brain injury, severe acquired brain injury, low functioning autism spectrum disorder, and Down's Syndrome. Symptoms of these conditions often include impaired cognition, which would have prevented the participant from being able to complete the required assessments without biasing test results. Additionally, individuals that met this criterion were excluded for safety purposes.

Each participant had the right to ask questions and have them answered before being included in this study. Participants also had the right to communicate their desire to withdraw from the study with no repercussions or costs whatsoever. Individuals with impaired 
communication skills who would be unable to indicate a desire to withdraw from the study were excluded from this study to protect their rights and safety.

Individuals without a current driver's license were also excluded from the study. The IMPS purports to measure pre-driving skills, and the EF-Car Motion Driving Simulator purports to measures one's driving ability. Therefore, the researchers desired a sample population consisting of individuals who have driving experience. Similar to the reason for the exclusion of individuals below the age of 18 , exclusion of those without an active driver's license restricted the sample to individuals who have driving experience.

A potential side effect of using the driving simulator is simulator sickness. Individuals who were aware that they are prone to suffer from motion sickness were excluded from the study. This exclusion was partly to prevent any discomfort to participants and to ensure each participant could complete both assessments fully. Despite taking this precaution, 4 out of the 36 participants experienced simulator sickness and had to stop the testing procedures.

\section{Assessments and Measures}

In this study, the IMPS and the EF-Car Motion Driving Simulator were used, and the concurrent validity between these two measures were explored.

\section{IMPS.}

The Indoor Mobility Pre-driving Screen (IMPS), formerly known as the Tracy Young Dynamic Assessment of Vision, was developed by Tracy Young, OTR/L, along with graduate students (Pope \& Tope, 2011). This assessment was developed out of the need for a screening tool that accurately measures dynamic vision. This screening tool purports to measure dynamic in a more accurate way while an individual navigates the environment as opposed to being in a 
fixed position. The IMPS assesses ten domains, including memory, attention, problem-solving, mobility, visual scanning at midline, scanning of the right visual field, scanning of the left visual field, acting on informational signs, wayfinding, and accuracy (Pope \& Tope, 2011).

Before the start of the study, the primary researcher was trained in the set-up, administration, and scoring of the IMPS by the principal investigator, Dr. Kaitlyn Cremer, MOT, OTD, OTR/L, SCLV who is well versed in the assessment. A location at the USAHS was determined for set-up and administration of the IMPS. All 36 participants completed the same IMPS course.

The IMPS is standardized; therefore, all participants were read the script of instructions provided in the IMPS testing form. Upon having the testing instructions read to them, participants were asked to repeat the instructions to screen their memory and ensure they understood the instructions. The instructions were repeated to the participant as needed. The number of repetitions required was taken into account and is reflected in the overall score of the IMPS. Once the participant initiated the course, they were required to attend to certain signs while ignoring others. The signs were placed at eye level on the left, on the right, and at midline to screen the individual's ability to scan their environment visually. Navigation of the course required wayfinding based on the posted signs and problem-solving to navigate back to the starting point.

Several studies have been conducted on the IMPS, thus far exploring the validity of the IMPS when compared to other assessments. Pope and Tope (2011) found there is a statistically significant relationship between the TYDAV and Symbol Digit Modalities Test (SDMT). They also explored the potential correlation between the TYDAV and the Posit Science Crash Risk Evaluator and the Comprehensive Trail Making Test (CTMT). No correlations were found 
between the TYDAV and these two assessments. Miles, Svay, Madrid, \& Crichton (2014) found significant correlations between the TYDAV and the Dynavision 2000, a tool used to assess useful field of vision (UFOV). Alhashmi, Hudson, Mendez-Schiaffino, \& Williford (2016) explored known groups validity of the TYDAV when investigating potential differences between individuals with and without acquired brain injuries (ABI). They found significant differences in TYDAV scores between individuals with and without ABI. The researchers also discovered a significant correlation in TYDAV total scores and Dynavision 2000 average speeds in all trials except one. Amos, McKown, \& Wilson, (2012) explored concurrent validity between the TYDAV and the SDMT, CTMT, and the Posit Science Crash Risk Evaluator in individuals with $\mathrm{ABI}$ and found no significant correlations.

\section{EF-Car Motion Driving Simulator.}

Driving simulators are becoming more common as a means of assessing an individual's capability to drive as an alternative to behind the wheel assessment. Lew et al. found that simulator-based assessment of patients with brain injuries can provide ecologically valid measures (2005). Meuleners and Fraser (2015) concluded that their preliminary results provide support for the relative validity of the driving simulator. Ultimately though, there is mixed evidence on the validity of driving simulators as a means of driving assessment (Wynne, Beanland, \& Salmon, 2019). There are many different driving simulators, each with distinct programming, fidelity, and validity when testing the many facets crucial to safe driving. Current research regarding their validity is mixed (Martin-Delos Reyes et al., 2019; Wynne, Beanland, \& Salmon, 2019). Driver simulators can provide a safer, more controlled alternative to BTW assessments (Dickerson, 2014). Data specific to the EF-Car Motion Driving Simulator by 
Simulator Systems International is not available in the literature. Furthermore, there is no data or studies done on this particular system on the manufacturing company's website.

\section{Procedures for Data Collection}

Prior to the start of the study, approval from the USAHS institutional review board was obtained by the researchers. After initial contact and screening for acceptance into the study, each participant was scheduled for a one-hour session at the USAHS St. Augustine campus. Before being evaluated by both measures, each participant was provided an informed consent waiver, which they reviewed and signed before any other procedures were conducted. Individuals with impaired cognition, such as those who suffered cerebrovascular accidents or traumatic brain injuries, were required to have the waiver signed by a legally authorized representative (LAR). All 36 of the participants in this study were cognitively sound enough to comprehend and sign all of the forms. While the LAR provision was there in the paperwork, it was not utilized by any of the participants.

Following the completion of the informed consent waiver, the participant was provided with a demographic form to complete. Participants provided personal information such as age, gender, number of years driving, weekly driving frequency, time of day when they drive, if they wear glasses or corrective lenses while driving, and known health conditions. The collection of this data was necessary for the completion of descriptive statistics during data analysis. After these two forms were completed, assessment administration began.

The principal investigator in this study is well versed in the IMPS, and EF-Car Motion Driving Simulator and trained the primary researcher in their administration and scoring. Administration of the IMPS was conducted by the student researcher with the aid of a graduate 
student volunteer. During the assessment administration process, recording and scoring of data was the sole responsibility of the primary researcher. Consistency in scoring and data collection was important for unbiased results. By leaving data recording and scoring the responsibility of one person, bias was prevented from entering into the study in the form of poor inter-rater reliability. The role of the student volunteer was to assist the primary researcher by walking alongside each participant while providing stand-by assist to ensure participant safety. Removing this responsibility from the primary researcher allowed the primary researcher to focus on observing the participant's performance and recording data during the assessment. The design of these procedures assisted in maintaining the accuracy of all gathered and recorded data.

The total administration time of the IMPS lasted approximately 5-10 minutes. The standardized script of instructions was followed when providing instructions to each participant. Comprehension of the instructions was verified by asking the participant to recite them back to the primary researcher. The IMPS does account for the number of repetitions of the instructions and accounts for that in the overall score. After demonstrating an appropriate understanding of the instructions, each participant was informed that their trial was going to be timed. Participants were instructed to complete the course as quickly as possible while keeping a safe pace. The participant then embarked on the $125-175$ feet course. While navigating the course to the designated destination, the participant had to visually scan their environment to identify the posted signs. Participants were instructed to indicate the posted signs by verbalizing what was on each sign and by pointing to it. These signs, printed on $5 \times 7$ " notecards, were either directional in the form of arrows, or had words on them such as "Rm 105." Upon reaching the destination at the halfway point of the course, the participant then navigated back to the beginning of the course while continuing to identify signs along the route. The assessment concluded when the 
participant reached the starting point. Data collected by this tool was recorded and later analyzed using statistical tests in the form of correlations.

The administration of the EF-Car Motion was conducted solely by the primary researcher. This process included the administration of 5 distinct assessments: reaction time, cognitive abilities, field of view, glare/memorization, and situational awareness. These five programs were selected because the IMPS purports to measure similar client factors. Data collected included the number of driving errors, reaction time in seconds, and percentage accuracy of identifying objects. Variables considered by the EF-Car Motion Driving Simulator during testing were calculated by the machine and displayed on the main monitor. This data was recorded on a data collection sheet. Data collected was used for statistical tests in the form of correlations during data analysis.

A script of instructions was created by the researcher to provide consistency in the study and to expand upon the brief, non-comprehensive instructions provided by the driving simulator. Each participant was oriented to the driving simulator prior to the administration of the simulator-based assessments. This orientation included a description of the location and function of the hardware components of the machine, including steering wheel, brake pedal, clutch, throttle, horn, turn signals, seat belt, and seat adjustment levers. The participant was then instructed to sit in the simulator seat and adjust it as needed.

The first assessment performed on the driving simulator was titled reaction time. This assessment consisted of three trials, the results of which were then compiled into average reaction time. To measure reaction time, the machine simulated a driving scenario where the individual was placed on a straight and empty road. The participant then accelerated to limited 
speed of 40mph. A stop sign would then suddenly appear on a random location on the center screen. Upon seeing the stop sign, the participant would then stop as quickly as possible.

The second assessment performed on the driving simulator was titled cognitive abilities. This assessment can be done either with traffic on the road or without. For this study, the trial with traffic was chosen. Participants were instructed to drive at $55 \mathrm{mph}$ in the right lane on the highway. They were instructed not to veer out of the lane and to keep a steady speed of 55mph. After driving the length of the predetermined course, the participant was then instructed by the assessment to pull off to the side of the road and turn off the ignition.

The third assessment given on the EF-Car Motion Driving Simulator was titled field of view. Participants were instructed to fix their vision upon a rectangle in the middle of the center monitor for the duration of the assessment. They were then instructed to press the horn if they saw an object or shape appear on any of the three screens. After pressing the horn, the participant then told the researcher which screen and in which quadrant of the screen the shape appeared. The researcher then used the mouse attached to the driving simulator to select the zone indicated by the participant.

The next assessment given was titled glare/memorization. This assessment consisted of three trials of increasing difficulty. During the first trial, random letters appeared one at a time at random locations on the center screen until a horn sounded. The letters that appeared did not remain on display but rather disappeared before the next letter appeared. Upon hearing the horn, the participant then verbally indicated to the researcher the last letter they saw. The researcher then used the mouse attached to the driving simulator to select the letter indicated by the participant. The second trial was identical to the first, aside from a significant increase in the speed of appearance/disappearance of the letters. The third trial seemed to occur at the same rate 
as the second trial; however, the letters did not appear at random locations all over the center screen. Rather, the letters only appeared in one spot on the screen. The speed of letter appearance was as rapid as the second trial, but the rate of disappearance was slightly less, which created an overlay type effect on the letters.

The final assessment administered on the driving simulator was titled situational awareness. This assessment could take place in either a simulated country or city environment. The city variation of the assessment was used in this study. Participants were instructed that they were to drive in a city environment for approximately 5 minutes. During this drive, verbal instructions were provided to the participant by the simulator, similar to how a modern GPS provides auditory directions. Participants were told to follow the instructions provided to them during the assessment and to drive carefully. Participants were given directions through the environment that inevitably led them to a number of potentially hazardous situations such as pedestrians walking into the road unexpectedly, cars pulling out into the street with little warning, and drivers going well below the speed limit in no-passing zones.

Following the completion of the informed consent waiver, demographic form, and both assessments, each participant was thanked for their time and dismissed from the university. After data analysis was finished, participants were sent an email containing a thank you letter as well as their scores. The comparison of their scores to the group scores were provided in the form of ranges, means, and standard deviations.

\section{Safety and Confidentiality}

All data and informed consent waivers attained from participants during the study were kept strictly confidential. All documents with personal identifying information were scanned and 
stored electronically in a password-protected folder on a password-protected computer. The only exception was individual data emailed to each participant upon the conclusion of the study. Upon securing the documents electronically, the physical copies were destroyed. For example, informed consent forms were scanned, secured electronically, and then shredded. Participant's names were not reported or included in findings or the discussion in the final paper. Personal identifiers in the form of first name last initial remained attached to data until the completion of all data analysis in SPSS. While this was not ideal for confidentiality, it was necessary so the researchers could provide each participant with their specific scores upon completion of the study. After emailing results to the participants, personal identifiers attached to data were replaced with identifying numbers to create anonymity of the data.

All risks were clearly stated and made known to each participant, and every attempt possible was made to ensure their safety. Participants were briefed that anticipated risk was minimal. It was made know to each participant if, at any time, they felt they needed to stop or withdraw from the study, they could do so with no repercussions to themselves whatsoever. Participants were told that there was a potential risk of falling as they navigate the environment as required for assessment completion. To mitigate this risk, one of the researchers or the student volunteer remained with each participant at all times during the study. A gait belt was placed on each participant during the administration of the IMPS to ensure their safety. The IMPS course was checked and cleared of any obstacles that increased a participant's risk of falling. None of the 36 participants experienced a fall during testing procedures. If a participant were to have fallen, the participant would have been informed to contact a medical professional promptly. If a severe fall or accident had occurred, emergency medical services would have been contacted immediately. 
Participants were made aware of potential simulator sickness while being assessed with the EF-Car Motion Driving Simulator. Individuals prone to having motion sickness were excluded from the study; however, there was still a risk that participants might experience symptoms while completing the driving simulator testing. 4 out of 36 participants did experience simulator sickness. Upon notifying the researcher that they were feeling unwell, all procedures were stopped. Each participant that experienced simulator sickness was offered water, crackers, and a place to sit or lie down if they wished. Symptoms of simulator sickness wore off in approximately 5-20 minutes.

Additionally, participants were told that they might experience emotional distress upon receiving their testing results upon the conclusion of the study. Contact information was provided so they can reach out with any questions or concerns regarding their performance. Community resources were provided to any participant that wanted to know how they can improve their pre-driving skills.

\section{Data Analysis}

Following data collection, scores from the IMPS and the five measures utilized from the EF-Car Motion Driving Simulator were entered into SPSS along with the demographic data for statistical analysis. Descriptive statistics in the form of range, mean, and standard deviations regarding the demographic data (age and gender) were calculated and compared. Potential relationships between the two measures were addressed through the computation of Pearson $r$ correlations. Pearson's r correlations were also used for post hoc statistical analyses. Post hoc analyses were performed to explore any correlations age, and order of assessment had on the assessment scores. 


\section{Alignment with Project Objectives}

The objectives of this capstone project were addressed and accomplished through the exploration of the concurrent validity between the IMPS and the EF-Car Motion Driving Simulator. The administration of these assessments resulted in data crucial for the exploration of any correlations between the two measures. All data gathered was recorded and scored to perform statistical analysis later. Additionally, data gathered from participants on the demographic forms were compiled and analyzed using descriptive statistics. Statistical analyses in the form of descriptive statistics allowed researchers to explore potential relationships between demographic data. Furthermore, data analyses allowed the researcher to address the primary research question. The findings are discussed in chapter 4 of this paper. A presentation was developed by the primary researcher to disseminate the results.

\section{Timeline}

After obtaining approval from the University of St. Augustine for Health Sciences institutional review board (IRB), this capstone project was able to begin. The first four weeks of this experience were spent preparing the foundation for the study. The primary researcher spent time practicing administration of the IMPS and the programs of the EF-Car Motion Driving Simulator to ensure consistency throughout administration during the study. Also, the primary researcher, in conjunction with faculty, shared the informational flyer with community organizations, student organizations, and individuals at the USAHS pro-bono clinic. Additionally, time was spent during these weeks preparing materials, creating a data collection sheet, creating the notecards used in the IMPS, and reviewing SPSS. 
Weeks five through seven were spent marketing and recruiting participants for the study. Time was spent reaching out to community groups, faulty members of USAHS, running assessment trials, and recruitment of a student volunteer. Participant trials began on the eighth week and continued through the thirteenth week. During weeks 14-18, data logging and data analysis in the form of descriptive statistics and statistical tests such as Pearson's $r^{2}$ were completed. Additionally, the final manuscript and poster were created during this time. Furthermore, results were emailed to each participant following the completion of data analysis. Dissemination of the results also occurred at this time.

\section{Summary of Methodology}

The IMPS has the opportunity to fill the need for a valid standardized clinical screening tool of pre-driving ability. This study was necessary for furthering its validation through the establishment of concurrent validity in comparison to a driving simulator. The design utilized was nonexperimental, and participants were gathered using convenience sampling. All predetermined standardized protocols for assessment administration and data collection were adhered to strictly. Descriptive statistics were computed utilizing the demographic data gathered during data collection, and the relationship between the two measures was explored using a Pearson product-moment correlation. 


\section{Results}

\section{Introduction}

This study aimed to explore the concurrent validity of the Indoor Mobility Pre-driving Screen (IMPS). Concurrent criterion-related validity was examined through correlating scores of the IMPS with the scores of five assessments on the EF-Car Motion Driving Simulator. In addition to exploring relationships via correlations, exploratory analyses were performed to explore potential relationships between demographic variables and scores on the IMPS and assessments on the EF-Car Motion Driving Simulator. Possible relationships between specific domains of the IMPS and EF-Car Motion Driving Simulator were also explored.

\section{Demographic Data}

The convenience sample gathered in this study consisted of 36 participants $(n=12$ males, $\mathrm{n}=24$ females). Each participant completed a demographic form that included: age, gender, medical history, driving status, driving behavior (see Appendix C). Table 2 lists demographics for the total sample, including age, years driving, number of days driven per week, length of time per trip, and number of miles driven in a day. Efforts were made to gather a wide age range of participants of typical driving age to create a sample inclusive of multiple age groups. Shows the frequency of individuals in each age group who participated in the study. Despite efforts to stratify the sample based on age, convenience sampling was being utilized, thereby resulting in a study sample with unequal age group representation. The participant pool consisted of the following age groups: 20-29 $(n=5), 30-39(n=9), 40-49(n=2), 50-59(n=4), 60-69(n=11), 70-79$ $(n=2), 80-89(n=3)$. It is important to note that the most frequent age group was 60-69, with 11 participants followed by 30-39 with nine participants. 
In addition to the information detailed in table 2, participants reported data on hand dominance: right hand dominant $(n=32)$, left hand dominant $(n=3)$, and ambidextrous $(n=1)$. All 36 participants were licensed drivers at the time of participation in the study. 33 out of 36 drivers were current drivers at the time of participation. Additionally, 18 participants indicated they wear glasses or contacts while driving, 17 participants indicated they do not, and one participant did not answer.

When asked about medical history on the demographic form, participants were presented with a list of medical diagnoses and were asked to circle all that apply. Since each participant was able to list all applicable diagnoses, 28 responses were provided by 14 participants. Seven $(n=7)$ individuals indicated they had only one diagnosis, four $(n=4)$ individuals indicated they had two diagnoses, two $(\mathrm{n}=2)$ individuals indicated they had three diagnoses, and one $(\mathrm{n}=1)$ individual indicated they had six diagnoses. These medical conditions included vision problems (6), hypertension (7), stroke (4), heart problems (1), sensory loss (3), orthopedic problems (3), arthritis (3), and memory/cognitive problems (1). Participants were allowed to select all diagnoses that applied to them, resulting in 17 responses generated by 13 participants. The most common pertinent medical diagnosis reported, which may affect driving was vision problems, indicated by six participants. It is important to note that the majority of participants $(n=22)$ were well off, community-dwelling individuals with no apparent disabilities

Participants were also asked if they had difficulty seeing while driving. 13 participants indicated they had difficulty seeing while driving, 22 indicated they did not, and one participant did not respond. If the participant answered yes, they were asked to indicate what environmental conditions (all that apply) impacted their ability to see while driving: day time, night time, rain, sunshine, and snow. 17 responses were generated by 13 participants, including night time (12), 
rain (4), and sunshine (1). Participants also provided information regarding driving demographics and behaviors such as primary purposes for driving, and types of roads typically traveled. Table 2 details descriptive statistics of the demographic variables.

\section{Table 2}

Descriptive Statistics of Demographic Data

\begin{tabular}{|c|c|c|c|c|c|}
\hline Variable & $\mathrm{N}$ & Min & $\operatorname{Max}$ & Mean & SD \\
\hline Age in Years & 36 & 21 & 84 & 51.81 & 18.84 \\
\hline Years Driving & 36 & 5 & 66 & 34.58 & 17.738 \\
\hline Days per Week Driven & 33 & 2 & 7 & 6.18 & 1.489 \\
\hline Total Miles Driven per Day & 31 & 5 & 240 & 30.00 & 39.33 \\
\hline Average Time per Driving Trip (Mins) & 33 & 2 & 200 & 27.87 & 38.196 \\
\hline
\end{tabular}

\section{Descriptive Statistics of Assessment Scores}

Descriptive statistics were performed to analyze participant results on the IMPS and the EF-Car Motion Driving Simulator. Table 3 lists the results of the statistical tests performed on each of the 14 scoreable components of the IMPS, as well as the total time and total score. When looking at the IMPS total score, a good range of scores was produced by the sample group.

However, the mean was quite high, which is indicative of a sample of mostly healthy individuals. This is further reflected by the scores on the other sections of the IMPS as well.

\section{Table 3}

Descriptive Statistics on IMPS Scores

\begin{tabular}{llrrrr}
\hline \multicolumn{1}{c}{ IMPS Test Item } & N & \multicolumn{1}{c}{ Min } & \multicolumn{1}{c}{ Max } & \multicolumn{1}{c}{ Mean } & \multicolumn{1}{c}{ SD } \\
IMPS Total (out of 100) & 36 & 56 & 99 & 82.86 & 9.044 \\
IMPS total time (seconds) & 36 & ERROR & ERROR & ERROR & ERROR \\
IMPS Memory & 36 & 4 & 4 & 4 & 0.000 \\
IMPS Alternating Attention & 36 & 3 & 3 & 3 & 0.000 \\
IMPS Problem Solving & 36 & 2 & 3 & 2.94 & 0.232 \\
\hline
\end{tabular}




\begin{tabular}{llrrrr}
\hline IMPS Head Mobility & 36 & 2 & 3 & 2.97 & 0.167 \\
IMPS Scanning Midline & 36 & 2 & 2 & 2.00 & 0.000 \\
IMPS Scanning Right & 36 & 0 & 2 & 1.22 & 0.832 \\
IMPS Scanning Left & 36 & 0 & 2 & 1.36 & 0.683 \\
IMPS Acting on Informational Signs & 36 & 3 & 3 & 3.00 & 0.000 \\
IMPS Way Finding & 36 & 3 & 5 & 4.94 & 0.333 \\
IMPS Accuracy to Destination & 36 & 9 & 12 & 11.11 & 0.919 \\
IMPS Accuracy to Start & 36 & 9 & 12 & 11.33 & 0.828 \\
IMPS Accuracy Right & 36 & 7 & 10 & 9.14 & 0.990 \\
IMPS Accuracy Left & 36 & MISSING & MISSING & MISSING & MISSING \\
IMPS Accuracy Midline & 36 & ERROR & ERROR & ERROR & ERROR \\
\hline
\end{tabular}

Descriptive statistics were also performed on participant results on the five assessments conducted on the EF-Car Motion driving simulator: reaction time, cognitive abilities, field of view, glare/memorization, and situational awareness. Table 4 details the results of those analyses.

\section{Table 4}

Descriptive Statistics on Driving Simulator Scores

\begin{tabular}{lrrrrr}
\hline \multicolumn{1}{c}{ Driving Simulator Test Item } & N & \multicolumn{1}{c}{ Min } & Max & Mean & SD \\
Reaction Time Assessment & \multicolumn{1}{c}{ Maction time trial 1 } & 0.6 & 3.7 & 1.040 & 0.610 \\
$\quad$ Reaction time trial 2 & 36 & 0.5 & 1.4 & 0.800 & 0.199 \\
Reaction & 36 & 0.5 & 3.8 & 0.803 & 0.543 \\
Reaction time trial 3 & 36 & 0.5 & 2.2 & 0.881 & 0.360 \\
Reaction time average & & & & & \\
Cognitive Abilities Assessment & 36 & 0 & 6 & 0.86 & 1.417 \\
Number of Times Over Speed Limit & 36 & 0 & 7 & 2.53 & 1.990 \\
Number of Times Under Speed Limit & 36 & 0 & 12 & 3.75 & 2.781 \\
Veering to the Right & 36 & 0 & 6 & 1.28 & 1.667 \\
Veering to the Left & 36 & 0 & 100 & 76.75 & 27.457 \\
Maintained Appropriate Speed (\%) & 36 & 17 & 100 & 76.75 & 27.457 \\
Stayed on Course (\%) & & & & & \\
Field of View Assessment & 35 & 13 & 20 & 18.77 & 1.664 \\
Objects Identified & 35 & 65 & 100 & 88.29 & 10.977 \\
Correct Location (\%) & & & &
\end{tabular}




\begin{tabular}{llllll}
\hline $\begin{array}{l}\text { Incorrect Location (\%) } \\
\text { Glare/Memorization Assessment }\end{array}$ & 35 & 0 & 25 & 5.57 & 6.156 \\
Glare/Memorization Trial 1 & 35 & 3 & 4 & 3.91 & 0.284 \\
Glare/Memorization Trial 2 & 35 & 2 & 3 & 2.97 & 0.169 \\
Glare/Memorization Trial 3 & 35 & 2 & 3 & 2.97 & 0.169 \\
Situational Awareness Assessment & & & & & \\
Insufficient Separation Gap & 35 & 2 & 19 & 8.86 & 4.747 \\
Turn Signal Errors & 35 & 0 & 9 & 2.74 & 2.063 \\
White Line Errors & 35 & 0 & 3 & 1.57 & 0.815 \\
Inappropriate Action at Junction & 35 & 0 & 1 & 0.29 & 0.458 \\
Speeding & 35 & 0 & 4 & 0.74 & 0.458 \\
Lane Discipline & 35 & 0 & 2 & 0.43 & 0.608 \\
Wrong Direction & 35 & 0 & 2 & 0.46 & 0.611 \\
Collisions & 35 & 0 & 5 & 2.14 & 1.353 \\
Hazards Negotiated & 35 & 3 & 7 & 6.09 & 1.067 \\
\hline
\end{tabular}

Note. One participant stopped testing procedures at the end of the cognitive abilities assessment, as seen by $\mathrm{N}$, decreasing from 36 to 35 .

Some measure of learning can be seen in the reaction time assessment data (Table 4). A decrease in the mean of 0.2 seconds occurred between the first trial and the second trial. The third trial also had a significantly lower mean than the first trial. The high outlier score during the third trial of testing elevated the mean to a value greater than that of the second trial. It should be noted that if that outlier was removed, the mean and standard deviation of the third trial would be lower than that of the second.

There were large ranges present on the scores of the second driving simulator assessment, cognitive abilities (Table 4). However, the means for each of the testing items are again indicative of a relatively healthy testing population. A few outliers exist in this data set, such as $0 \%$ success maintaining speed and $17 \%$ success staying on course, which lowered the mean and increased standard deviation.

A very small range exists on all three trials of the glare/memorization assessment. Additionally, the means are very high, and the standard deviations very low. The majority of 
individuals performed very well on this assessment regardless of their reported medical conditions.

\section{Results Related to the Primary Research Question}

This study explored the concurrent validity of the IMPS and five rehabilitative assessments on the EF-Car Motion Driving Simulator. Pearson product-moment correlations were performed between the IMPS total score and each of the testing items of the EF-Car Motion Driving Simulator. The results of these correlations are detailed below in Table 5.

\section{Table 5}

Pearson Correlations of IMPS Total Score with Driving Simulator Scores

\begin{tabular}{lccc}
\hline & Correlation & $p$-value & Significant \\
\hline Reaction Time Assessment & & & \\
$\quad$ Reaction Time Average & -.196 & .251 & No \\
Cognitive Abilities Assessment & & & \\
Number of Times Over Speed Limit & $-.384^{*}$ & .021 & Yes \\
Number of Times Under Speed Limit & -.186 & .278 & No \\
Veering to the Right & $-.359 *$ & .032 & Yes \\
Veering to the Left & .042 & .808 & No \\
Maintained Appropriate Speed (\%) & .299 & .076 & No \\
Stayed on Course (\%) & .041 & .812 & No \\
Glare/Memorization Assessment & & & \\
Glare/Memorization Trial 1 & .047 & .788 & No \\
Glare/Memorization Trial 2 & .199 & .252 & No \\
Glare/Memorization Trial 3 & .180 & .301 & No \\
Field of View Assessment & & & \\
Objects Identified & $.469 * *$ & .004 & Yes \\
Correct Location of Objects & $.429 *$ & .010 & Yes \\
Situational Awareness Assessment & & & \\
Insufficient Separation Gap & -.139 & .426 & No \\
Turn Signal Errors & -.302 & .078 & No \\
White Line Errors & .051 & .773 & No \\
Inappropriate actions at Junctions & $-.349 *$ & .040 & Yes \\
Number of Times Over the Speed Limit & .274 & .111 & No \\
Lane Discipline & -.144 & .408 & No \\
Wrong Direction & -.007 & .969 & No \\
Number of Collisions & -.061 & .726 & No \\
Hazards Negotiated & .046 & .792 & No \\
\hline F & & &
\end{tabular}

$* \mathrm{p}<.05$

$* * \mathrm{p}<.01$ 
The IMPS generated a grand total in the form of the total score out of 100, representative of overall performance on the measure. The assessments that the IMPS was compared to do not generate a total score that represents performance. Two correlations were found between the IMPS total score and testing items of the cognitive abilities assessment. Negative correlations were found between the IMPS total score and the number of times over the speed limit $(\mathrm{r}=-.384$, $p=.021)$ and veering to the right $(\mathrm{r}=-.359, p=.032)$. The IMPS purported to measure cognitive factors such as wayfinding, processing, memory, and problem-solving, which is why it was compared to a cognitive abilities assessment.

Pearson correlations were also run between each of the IMPS test items and cognitive abilities test items. A statistically significant correlation was present between IMPS scanning right and staying on course $(\mathrm{r}=.332, p .048)$. IMPS scanning left was also compared to the same constructs. A negative correlation was present between IMPS scanning left and the number of times over the speed limit $(\mathrm{r}=-.390, p=.019)$. Participants were instructed to stay in the right lane for the duration of this assessment. A possible explanation for this correlation is that individuals who followed the instruction and maintained a right lane position demonstrated a higher level of awareness than those who did not maintain a right lane position. Participants who maintained the appropriate lane position might have had to scan the left side of the road more frequently than individuals who switched to either the middle or far left lane. It is possible that individuals with a higher level of awareness are also more aware of their speed, thus resulting in an inverse relationship between the two variables. Another Pearson correlation was conducted between IMPS accuracy right and constructs of the cognitive abilities assessment. IMPS accuracy right was found to be negatively correlated with veering to the right ( $\mathrm{r}=-.340, p=.043)$. It is logical that 
participants who performed well on IMPS accuracy right would have fewer episodes of veering to the right.

Correlations run between the IMPS total score and FOV assessment variables resulted in two statistically significant results. IMPS total score positively correlated to number of objects identified $(\mathrm{r}=.469, p=.004)$ and correct location of objects $(\mathrm{r}=.429, p=.010)$. Furthermore, in addition to correlating the IMPS total score to FOV scores, specific variables of the IMPS were also compared to the FOV variables by using Pearson product-moment correlations. IMPS scanning right was significantly correlated with FOV object identified $(\mathrm{r}=.369, p=.029)$ and correct location of objects $(\mathrm{r}=.428, p=.010)$. IMPS accuracy right was also significantly correlated with FOV objects identified $(\mathrm{r}=.366, p=.031)$ and correct location of objects $(\mathrm{r}=.368$, $p=.030)$. IMPS accuracy left also showed statistically significant correlations to FOV objects identified $(\mathrm{r}=.518, p=.001)$ and correct location of objects $(\mathrm{r}=.393, p=.02)$. These results are not necessarily surprising; however, it is interesting to consider the different nature of these two assessments. There is a heavy focus on visual scanning during completion of the IMPS, while visual scanning was prohibited during FOV testing. Despite that, there were significant correlations between these two measures.

IMPS total score was compared to testing variables of the driving simulator situational awareness assessment. Only one of the nine variables in this assessment correlated to the IMPS total score. A Pearson's correlation shows a significant negative correlation between IMPS total score and inappropriate action at junctions $(\mathrm{r}=-.349, p=.04)$. Individuals who performed highly on the IMPS were less likely to make a wrong turn while following the directions given during the situational awareness assessment. A possible explanation of this result is that individuals with a greater mastery of alternating/divided attention were less likely to make a wrong turn and more 
likely to score higher on the IMPS. However, when considering the IMPS constructs, all participants in this study scored the maximum number of points on the alternating attention construct of the IMPS. One would think that there would be a range of scores for alternating attention on the IMPS if there were varying alternating attention abilities within the participant pool. However, since none of the participants had any sort of significant cognitive problems, the IMPS may not have been difficult enough to provoke a poor performance on that particular construct. On the other hand, many more distractions were present during the situational awareness assessment on the driving simulator.

\section{Post Hoc Analysis}

After completion of the Pearson correlations necessary for answering the primary research question, post hoc analyses were performed to explore any existing relationships between age and testing constructs of both assessments. A Pearson correlation was conducted to determine if age was correlated to total scores on the IMPS. A negative correlation of $(\mathrm{r}=-.378$, $p=.023$ ) was found, meaning younger participants scored higher than older participants. Pearson product-moment correlations were also run for age in relation to maintaining speed on the cognitive abilities assessment $(\mathrm{r}=-.536, p=.001)$, number of objects identified during the FOV assessment $(\mathrm{r}=-.421, p=.012)$ and number of collisions during the situational awareness assessment $(\mathrm{r}=-.372, p=.028)$. All of the correlations revealed are negative, indicating that older participants may have decreased client factors in comparison to younger participants.

Potential relationships between the order of assessment administration and IMPS total score were explored through a paired sampled correlation. No correlation was found between the order of assessment and IMPS total score $(\mathrm{r}=-.154, p=.369)$. Additionally, the mean of IMPS 
total score was 84.64 for the group who took the IMPS first and 81.11 for the group that took the IMPS second.

\section{Limitations}

Several limitations were present in this study. One limitation of this capstone project was the limited sample size. A larger sample size representative of the overall population of drivers in the U.S. would have been optimal for exploring potential relationships of scores. Another limitation is that all of the recruited participants are from the same general geographical location, thus limiting external validity. Additionally, random sampling would have been a less biased method of participant recruitment and would have improved the overall study design. The number of females who participated in the study was double the number of males, and the majority of participants were Caucasian. Individuals of legal driving age under the age of 18 (1617) were excluded for convenience sake. Inclusivity of this population would have improved the sample.

Due to the setup location of the IMPS, participants had to travel through approximately $25 \%$ of the course prior to getting to the initial starting location. While attempts were made by the researchers to distract the participants as to not bias the results with foreknowledge of placement, some participants did notice the signs and even asked what they were there for. Furthermore, when being read the script of instructions, several of the participants were observed to be looking ahead and attempting to spot signs prior to starting.

Some minor improvements to the IMPS script of instructions could be made. The instructions initially state, "I want you to call out and read aloud every one of the white signs you see." Further along in the script, after asking the participant to repeat the instruction back, the 
test administrator reviews the instructions with the participant. At that point, the instructions state, "Call out and point to every white sign along the way and on the way back to the start." Some participants missed that part of the review and did not realize they were supposed to point out signs as well as call them out. This slight discrepancy in the instructions caused confusion for several participants. Adding the "and point to" portion to the first iteration of the instructions would provide clarity.

There were also limitations in regards to the administration of the driving simulator assessments. First, the instructions for the FOV assessment are quite vague and do describe the full procedures of the assessment. The instructions that were displayed on-screen merely told the participant to stare at the center of the center screen and press the horn when they see an object appear. After each time the horn is pressed, the individual must then indicate on which of the three monitors and in what quadrant of the screen the object appeared. Even with the researcher providing additional instructions, several participants experienced confusion on this assessment. Another possible limitation of the driving simulator was the sensitivity of the steering wheel, brakes, and throttle.

Many participants complained that the steering and brakes were too sensitive and that the throttle was not sensitive enough on the driving simulator. Primarily, while no qualitative data was gathered during the study, it seemed as though older participants had a more difficult time adjusting to a sensitivity that was different than their own vehicle. The researchers were unable to find a setting that would allow sensitivities to be adjusted. There was also a limitation with the cognitive abilities assessment. As the participant draws near to the end of the assessment, all of the screens on the simulator would go black without warning, and the assessment would pause. After approximately 30 seconds, the screens would come back on without warning, and the 
individual would still be on the road, traveling at the same speed they were when the assessment paused. While the cause of the "blackout" is not known to the researchers, it is assumed that at that point, the driving simulator was creating the score report for that assessment prior to its completion. It appeared that driving errors made after that point in time were not recorded.

Finally, participant dropout, while unanticipated, did occur during the study. Four participants experienced simulator sickness during the course of testing and had to stop the procedures during the midst of the situational awareness assessment. One participant stopped the testing procedures after completing the second DS assessment and did not complete the rest of the DS assessments.

\section{Delimitations}

Delimitations present in this capstone project included the inclusion criteria, exclusion criteria, quantitative design, and the programs of the driving simulator selected for comparison. These boundaries had to be drawn to make the project feasible to answer the posed research question in the short time frame and with the resources available to the researchers.

\section{Conclusion}

The purpose of this study was to evaluate the concurrent validity of the IMPS in relation to assessments on the EF-Car Motion Driving Simulator. To answer the primary research question, is there a correlation between scores on the IMPS and the EF-Car Motion Driving Simulator, statistical analysis was performed in the form of Pearson $r$ correlations. Results of these statistical tests showed scores on the IMPS correlate with some scores on the driving simulator. While some correlations were present, there was not a high level of correlation found 
between these two tools. Further discussion of the results and their implications will occur in the following section of the paper. 


\section{Discussion}

\section{Introduction}

The purpose of this study was to explore the concurrent validity between the IMPS and EF-Car Motion Driving Simulator rehabilitative programs. Descriptive statistics were used to understand better the constructs of the assessments used, as well as demographic data reported by participants in the sample. Statistical tests in the form of Pearson's product-moment correlations were performed to address the primary research question. Post hoc correlations were also conducted to explore potential relationships between age and assessment scores, and order of assessment and IMPS total score. Some weak to moderate correlations were found between constructs on the IMPS and constructs of the various driving simulator assessments. However, no strong correlations were found. No correlations existed between the IMPS and the first driving simulator (DS) assessment, reaction time. Five low to moderate correlations exist between test items on the IMPS and the cognitive abilities DS assessment. No correlations are present between the glare/memorization DS assessment and the IMPS. The greatest number of correlations exists between the IMPS and the DS field of view assessment. Only one moderate correlation was found between the IMPS total score and variables in the DS situational awareness assessment.

\section{Interpretation of Findings}

Overall, the findings of this study show that scores on the IMPS are only slightly correlated to scores on the EF-Car Motion Driving Simulator assessments. When comparing the IMPS to the first driving simulator assessment, reaction time, no correlations were found. This is because reaction time is not a skill directly measured by the IMPS. This is important information 
for future administrators of the IMPS. Reaction time is an important skill needed for braking quickly and reacting to unanticipated events while driving. Practitioners should be aware that the IMPS does not measure reaction time, and they would need to administer a different assessment to assess it.

Upon comparing the IMPS total score to variables on the driving simulator cognitive abilities assessment, two correlations were found. The IMPS total score was correlated to the number of times individuals went over the speed limit during the cognitive abilities assessment $(\mathrm{r}=-.384, p=.021)$. Pearson correlations also show there is an inverse relationship between IMPS total score and the number of times individuals veered to the right ( $\mathrm{r}=-.359, p=.032)$. These results indicate that the IMPS does measure some aspects of cognition. Furthermore, the IMPS could potentially be predictive of two negative driving behaviors, speeding and veering to the right, during an on the road assessment. However, it is not possible to say that it is predictive of speeding with this data alone. The IMPS must be compared to an on the road driving assessment to truly evaluate its level of predictability.

The IMPS was compared to two visual assessments on the EF-Car Motion Driving Simulator, glare/memorization and field of view (FOV). Nearly all of the participants in this study achieved the maximum score on the glare/memorization assessment, despite their health condition. Therefore, it is only logical that no correlations were found between IMPS total scores and the glare/memorization assessment. It is likely that only specific populations such as those with significant cognitive or visual deficits would do poorly on that simulator assessment. Individuals with such significant, and likely apparent, deficits are unlikely candidates for a driving or pre-driving assessment. The IMPS total score was correlated to both variables of the 
FOV assessment, objects identified $(\mathrm{r}=.469, p=.004)$ and correct location of objects $(\mathrm{r}=.429$, $p=.01)$. These results confirm the IMPS does measure aspects of an individual's visual ability.

One negative correlation was found when comparing IMPS total scores to the variables

of the driving simulator situational awareness assessment. IMPS scores were inversely related to the number of inappropriate actions at junctions $(\mathrm{r}=-.349, p=.04)$. Making a correct turn at a junction is a matter of cognitive processing and executive functioning, skills the IMPS purports to measure in some capacity.

\section{Implications for Occupational Therapy}

The results of this study reveal minor correlations between the IMPS and the assessments on the EF-Car Motion Driving Simulator. Literature agrees upon the need for an in-clinic assessment that is predictive of on the road driving performance. Unfortunately, based solely on the results of this study, it is unlikely that the IMPS can fulfill this role in its current state. It is impossible to make such a statement with any kind of certainty until a study is conducted exploring the concurrent validity of the IMPS and an on the road driving assessment.

Occupational therapy practitioners should continue to work on the development of a clinic based assessment that is predictive of on the road outcomes, or improve upon those that already exist to better serve the population of individuals seeking driving assessment and rehabilitation. Furthermore, more research needs to be conducted on driving simulators to better establish their predictability and to improve upon the faults inherent in their design. Driving simulators are the future of driving assessment as they are the closest things we have to an on the road assessment. Until an assessment predictive of on the road outcomes is found, individuals seeking driving rehabilitation will have to rely upon the validity of assessments currently 
available for use. Drivers with disabilities will have to continue to seek out places where they can partake in on the road driving assessments.

\section{Implications for Future Research}

This research focused mainly on typical participants, and the participants who did have medical diagnoses were mostly well off or had only moderate to no apparent symptoms. In a clinical setting, these assessments would likely be administered to more medically involved individuals. It is recommended that future studies on the IMPS attempt to include participants with a variety of diagnoses with differing levels of involvement. Furthermore, it would improve study design and improve validity by having a larger sample size with a more evenly spread age distribution. Minor improvements could be made to the IMPS instructions to provide more clarity to the individual taking the assessment.

While the IMPS is intended to be an in-clinic assessment that can be set up almost anywhere, there is a lot of freedom given to the test administrator where they want to set up the assessment. Assessment location could either increase or decrease the difficulty of the IMPS. For example, setting it up in a more highly trafficked area would result in a greater number of distractions for the participant, potentially causing the participant to achieve lower scores. Furthermore, there is no spacing suggestions or instructions for setting up the signs. Depending on the setup location, contrast, figure-ground, and other objects on the walls may make it more challenging to recognize the signs. The location of doors, sharp turns, and shelving/objects close to the wall in relation to sign position could increase or decrease the difficulty of spotting the signs. 
The IMPS was compared to a driving simulator in this study. While concurrent validity between these two assessments was important to explore, concurrent validity of the IMPS needs to be explored in comparison to an on the road assessment of driving ability. To truly explore the IMPS' ability to predict on the road driving behavior, concurrent validity related to on the road driving assessment must be explored.

\section{Conclusion}

The purpose of this study was to explore the relationship between scores on the IMPS and assessments on the EF-Car Motion Driving Simulator. There is a degree of concurrent validity between the two measures; however, it is less than what was expected by the researchers. While both tools purport to measure similar skills, the way in which they are tested is very different. IMPS domains with the most correlations to scores on the driving simulator include total score, scanning right, scanning left, accuracy right, and accuracy left.

The IMPS purports to measure many skills needed for occupational success for both driving and other occupations as well. Occupational success, particularly with driving, promotes a lifestyle and feelings of independence, worth, and self-efficacy for individuals. There currently is no standardized in-clinic assessment that is predictive of on the road outcomes. The IMPS could still fill that gap if proven to be predictive of those outcomes. However, for that to happen, the concurrent validity of this tool needs to be further explored. The IMPS should be relevant to occupational therapists who specialize in driving rehabilitation as well as the occupational therapy generalist. As of now, therapists often use a battery of clinical assessments to attempt to predict on the road outcomes. The researchers conclude that further exploration of the validity and predictability of the IMPS is justified due to the potential benefit of a standardized in-clinic assessment of pre-driving skills that is predictive of on the road outcomes. 


\section{References}

Aduen, P. A., Kofler, M. J., Cox, D. J., Sarver, D. E., \& Lunsford, E. (2015). Motor vehicle driving in high incidence psychiatric disability: Comparison of drivers with ADHD, depression, and no known psychopathology. Journal of Psychiatric Research, 64, 59-66. doi:https://doi.org/10.1016/j.jpsychires.2015.03.009

Alhashmi, D., Hudson, N., Mendez-Schiaffino, M., \& Williford, C. (2016) Known groups validity of the Tracey Young Dynamic Assessment of Vision (TYDAV) (Unpublished master thesis). Brenau University, Georgia.

American Occupational Therapy Association [AOTA]. (2014). Occupational therapy practice framework: Domain and process. American Journal of Occupational Therapy, 68(Suppl. 1), pp. S1-S48. doi:http://doi.org/10.5014/ajot.2014.682006

American Occupational Therapy Association [AOTA]. (2017). The occupational therapy role in driving and community mobility across the lifespan. Retrieved from AOTA: https://www.aota.org/About-Occupational-Therapy/Professionals/PA/Facts/DrivingCommunity-Mobility.aspx

American Occupational Therapy Association. (2017). Occupational therapys role in adult cognitive disorders. Retrieved 10 03, 2019, from AOTA: https://www.aota.org/ /media/Corporate/Files/AboutOT/Professionals/WhatIsOT/PA/Fac ts/Cognitive-Disorders-Fact-Sheet.pdf

American Stroke Association. (n.d.) About Stroke. Retrieved 10 10, 2019, from https://www.stroke.org/en/about-stroke 
Amos, C. E., McKown, J. A., \& Wilson, P. S. (2012). Validation of the Tracy Young Dynamic Assessment of Vision (TYDAV) within a population of drivers with acquired brain injuries (Unpublished master's thesis) Brenau University, Gainesville, GA.

Association for Driver Rehabilitation Specialists. (n.d.). CDRS vs DRS. Retrieved 10 05, 2019, from ADED: https://www.aded.net/page/230

Barco, P. P., Wallendorf, M. J., Snellgrove, C. A., Ott, B. R., \& Carr, D. B. (2014). Predicting road test performance in drivers with stroke. American Journal of Occupational Therapy, 68(2), 221-229. doi:https://doi.org/10.5014/ajot.2014.008938

Bhorade, A. M., Yom, V. H., Barco, P., Wilson, B., Gordon, M., \& Carr, D. (2016). On-road Driving Performance of Patients With Bilateral Moderate and Advanced Glaucoma. American Journal of Ophthalmology, 166, 43-51. https://doi.org/10.1016/j.ajo.2016.02.031

Bishop, H., Stavrinos, D., Boe, L., \& Mirman, J. (2018). Driving among adolescents with autism spectrum disorder and attention-deficit hyperactivty disorder. Safety, 4(40), 1-26. doi:10.3390/safety4030040

Bonnel, W. B. (1999). Giving up the car: older women's losses and experiences. Journal of Psychosocial Nursing \& Mental Health Services, 37(5), 10-45. Retrieved from http://search.ebscohost.com/login.aspx?direct=true \&db=ccm\&AN=107198170\&site=eds -live

Carr, D. B., \& Ott, B. R. (2010). The older driver with cognitive impairment. JAMA, 303(23), 2357. doi:10.1001/jama.2010.481 
Centers for Disease Control and Prevention. (n.d.). Disability and Health. Retrieved 10 05, 2019, from Centers for Diseas Control and Prevention: https://www.cdc.gov/ncbddd/disabilityandhealth/infographic-disability-impacts-all.html

Cooney, T. M., Curl, A. L., Proulx, C. M., \& Stowe, J. D. (2014). Giving up the keys: how driving cessation affects engagement in later life. The Gerontologist, (3), 423. https://doi.org/10.1093/geront/gnt037

Crizzle, A., Hatzifilalithis S., Laberge, S., Naglie, G., Rapoport, M. J., Sanford, S., \& Tuokko, H., (2019). Independence, loss, and social identity: Perspectives on driving cessation and dementia. Dementia (14713012), 18(7/8), 2906-2924. https://doi.org/10.1177/1471301218762838

Dattoma, L. L. (2017). Evaluation of the older driver. Primary Care: Clinics in Office Practice, 44(3), 457-467. doi:https://doi.org/10.1016/j.pop.2017.05.003

Dickerson, A. (2013). Driving assessment tools used by driver rehabilitation specialists: Survey of use and implications for practice. American Journal of Occupational Therapy, 67(5), 564-573. doi:Https://doi.org/10.5014/ajot.2013.007823

Dickerson, A. (2014). Screening and assessment tools for determining fitness to drive: A review of the literature for the pathways project. American Journal of Occupational Therapy, 28(2), 82-121. doi:doi:10.3109/07380577.2014.904535

Dickerson, A., \& Davis, E. S. (2012). Welcome to the team! Who are the stakeholders? In M. J. McGuire, \& E. S. Davis (Eds.), Driving and community mobility: Occupational therapy strategies across the lifespan (pp. 49-78). Bethesda, MD: AOTA Press. 
Driver Knowledge. (2017). Car accident statistics in the U.S. Retrieved 10 03, 2019, from https:/www.driverknowledge.com/car-accident-statistics/

Driving and community mobility. (2010). American Journal of Occupational Therapy, S112-

S124. Retrieved from http://search.ebscohost.com/login.aspx?direct=true\&db=ccm\&AN=104349393\&site=eds -live

Eby, D. W., Molnar, L. J., \& Pellerito, J. M. (2006). Driving cessation and alternative community mobility. In J. M. Pellerito (Ed.), Driver rehabilitation and community mobility: Principles and practice (pp. 425-454). St. Louis, MO: Mosby, Inc.

Gamache, P.-L., Hudon, C., Teasdale, N., \& Simoneau, M. (2010). Alternative Avenues in the Assessment of Driving Capacities in Older Drivers and Implications for Training. Current Directions in Psychological Science, 19(6), 370-374. https://doi.org/10.1177/0963721410388641

Golisz, K. (2014). From the Desk of the Guest Editor - Occupational therapy and driving and community mobility for older adults. American Journal of Occupational Therapy, 68, 654-656. doi:http://dx.doi.org/10.5014/ajot.2014.01314

Green, E. (2019). Driver rehabilitation services and their role in the care plan. Journal of Nurse Life Care Planning, 15(2), 862-867. Retrieved from http://search.ebscohost.com/login.aspx?direct=true\&db=ccm\&AN=109635277\&site=eds -live 
Hasan, S., Chay, E., Atanda, A., McGee, J. A. W., Jazrawi, L. M., \& Zuckerman, J. D. (2015). The effect of shoulder immobilization on driving performance. Journal of Shoulder and Elbow Surgery, 24(2), 273-279. https://doi.org/10.1016/j.jse.2014.06.046

Hird, M. A., Egeto, P., Fischer, C. E., Naglie, G., \& Schweizer, T. A. (2016). A systematic review and meta-analysis of on-road simulator and cognitive driving assessment in Alzheimer's disease and mild cognitive impairment. Journal of Alzheimer's Disease, 53, 713-729. doi:10.3233/JAD-160276

Justiss, M. D. (2013). Occupational Therapy Interventions to Promote Driving and Community Mobility for Older Adults With Low Vision: A Systematic Review. American Journal of Occupational Therapy, 67(3), 296-302. https://doi.org/10.5014/ajot.2013.005660

Kaye, S.-A., Lewis, I., \& Freeman, J. (2018). Comparison of self-report and objective measures of driving behavior and road safety: A systematic review. Journal of Safety Research, 65, 141-151. https://doi.org/10.1016/j.jsr.2018.02.012

Krasniuk, S., Classen, S., Monahan, M., Danter, T., He, W., Rosehart, H., \& Morrow, S. A. (2019). A strategic driving maneuver that predicts on-road outcomes in adults with multiple sclerosis. Transportation Research Part F: Psychology and Behaviour, 60, 147156. doi:https://doi.org/10.1016/j.trf.2018.10.014

Kunishige, M., Fukuda, H., Iida, T., Kawabata, N., Ishizuki, C., \& MIyaguchi, H. (2019). Spatial navigation ability and gaze switching in older drivers: A driving simulator study. Hong Kong Journal of Occupational Therapy, 32(1), 22-31. Retrieved from

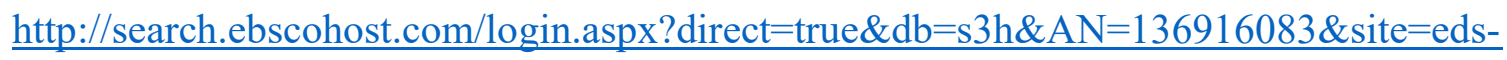
$\underline{\text { live }}$ 
Lacherez, P., Wood, J. M., Anstey, K. J., \& Lord, S. R. (2014). Sensorimotor and postural control factors associated with dricing safety in a community-dwelling older driver population. The Journals of Gerontology, Series A, 69(2), 240.

doi:https://doi.org/10.1093/gerona/glt173

Lew HL, Poole JH, Lee EH, Jaffe DL, Huang H, \& Brodd E. (2005). Predictive validity of driving-simulator assessments following traumatic brain injury: a preliminary study. Brain Injury, 19(3), 177-188. Retrieved from http://search.ebscohost.com/login.aspx?direct=true\&db=ccm\&AN=106381543\&site=eds -live

Macdonald, W., Pellerito Jr., J. M., \& Di Stefano, M. (2006). Introduction to driver rehabilitation and community mobility. In J. M. Pellerito Jr. (Ed.), Driver rehabilitation and community mobility: Principles and practice (pp. 3-22). St. Louis, MO: Mosby, Inc.

Martin-delosReyes, L. M., Jimenes-Mejias, E. J., Martinez-Ruiz, V., Moreno-Roldan, E., Molina-Soberanes, D., \& Lardelli-Claret, P. (2018). Efficacy of training with driving simulators in improving safety in young novice or learner drivers: A systematic review. Transportation Research Part F, 58-65. doi:https://doi.org/10.1016/j.trf.2018.12.006

Mayo Clinic. (n.d.) Stroke. Retrieved on 10 10, 2019, from https://www.mayoclinic.org/diseasesconditions/stroke/symptoms-causes/syc-20350113

Meuleners, L., \& Fraser, M. (2015). A validation study of driving errors using a driving simulator. Transportation Research Part F: Psychology and Behaviour, 29, 14-21. https://doi.org/10.1016/j.trf.2014.11.009 
Miles, R., Svay, J., Madrid, A., \& Crichton, A. (2014, December). Validation of the Tracy Young Dynamic Assessment of Vision (TYDAV): Comparison of the TYDAV and the Dynavision 2000 (Unpublished master's thesis). Brenau University, Georgia.

National Safety Council. (2018). Vehicle deaths estimated at 40,000 for third straight year. Retrieved from https://www.nsc.org/road-safety/safety-topics/fatality-estimates

NHTSA. (2017, October 6). USDOT releases 2016 fatal traffic crash data. Retrieved from https://www.nhtsa.gov/press-releases/usdot-releases-2016-fatal-traffic-crash-data

Niewoehner, P. M., Henderson, R. R., Dalchow, J., Beardsley, T. L., Stern, R. A., \& Carr, D. B. (2012). Predicting road test performance in adults with cognitive or visual impairment referred to a verterans affairs medical center driving clinic. Journal of the American Geriatrics Society, 60(11), 2070-2074. doi:https://doi.org/10.1111/j.15325415.2012.04201.x

O’Shea A., Woods A.J. (2018) Useful Field of View (UFOV). In: Kreutzer J., DeLuca J., Caplan B. (eds) Encyclopedia of Clinical Neuropsychology. Springer, Cham

Patomella A, Kottorp A, \& Tham K. (2008). Awareness of driving disability in people with stroke tested in a simulator. Scandinavian Journal of Occupational Therapy, 15(3), 184192. Retrieved from http://search.ebscohost.com/login.aspx?direct=true\&db=ccm\&AN=105693848\&site=eds -live

Pope, R. E., \& Tope, M. G. (2011). Validation of the Tracey Young dynamic assessment of vision (TYDAV) (Unpublished master's thesis). Brenau University. 
Portney, L. G. \& Watkins, M. P. (2015). Foundations of clinical research : applications to practice. Prentice-Hall, Inc. Retrieved from http://search.ebscohost.com/login.aspx?direct=true\&db=cat03948a\&AN=usa.4801\&site= eds-live

Powell, J. M. (2013). Traumatic Brain Injury. In Latham, C. T., \& Radomski, M. V. (Eds.), Occupational therapy for physical dysfunction. (pp. 1042-1075) Philadelphia Wolters Kluwer Health/Lippincott Williams \& Wilkins [2013].

Schreier, D. R., Banks, C., \& Mathis, J. (2018). Driving simulators in the clinical assessment of fitness to drive in sleepy individuals: A systematic review. Sleep Medicine Reviews, 38, 86-100. https://doi.org/10.1016/j.smrv.2017.04.004

Stapleton, T., Connolly, D., \& O'Neill, D. (2015). Factors influencing the clinical stratification of suitability to drive after stroke: A qualitative study. Occupational Therapy In Health Care, 29(3), 253-271. doi:10.3109/07380577.2015.1036192

Stav, W. B. (2015). Occupational therapy practice guidelines for driving and community mobility for older aldults. AOTA Press.

Stolwyk, R. J., Charlton, J. L., Ross, P. E., Bedard, M., Marshall, S., Gagnon, S., . . Ponsford, J. L. (2019). Characterizing on-road driving performance in individuals with traumatic brain injury who pass or fail an on-road driving assessment. Disability and Rehabilitation, 41(11), 1313-1320. doi:https://doi.org/10.1080/09638288.2018.1424955

Stressel, D., Hegberg, A., \& Dickerson, A. E. (2014). Driving for adults with acquired physical disabilities. Occupational therapy in health care, 28(2), 148-153.

doi:10.3109/07380577.2014.899415 
Szlyk JP, Mahler CL, Seiple W, Vajaranant TS, Blair NP, \& Shahidi M. (2004). Relationship of retinal structural and clinical vision parameters to driving performance of diabetic retinopathy patients. Journal of Rehabilitation Research \& Development, 41(3A), 347357. Retrieved from http://search.ebscohost.com/login.aspx?direct=true\&db=ccm\&AN=106670016\&site=eds -live

United States Department of Transportation. (2013). Licensed drivers. Retrieved from https://www.bts.gov/content/licensed-drivers

United States Department of Transportation. (2017). Highway Statistics 2017. Retrieved from: https://www.fhwa.dot.gov/policyinformation/statistics/2017/dv1c.cfm

U.S. Department of Transportation. (2018). Highway Statistics Series. Retrieved from U.S. Department of Transportation Federal Highway Administration: https:/www.fhwa.dot.gov/policyinformation/statistics/abstracts/2015/

United States Department of Transportation. (2018). Average annual miles per driver by age group. Retrieved from https://www.fhwa.dot.gov/ohim/onh00/bar8.htm

Unsworth, C. A., \& Baker, A. (2014). Driver rehabilitation: A systematic review of the types and effectiveness of interventions used by occupational therapists to improve on-road fitnessto-drive. Accident Analysis and Prevention, 71, 106-114. doi:http://dx.doi.org/10.1016/j.aap.2014.04.017

Unsworth, C. A., Baker, A., Lannin, N., Harries, P., Strahan, J., \& Browne, M. (2019). Predicting fitness-to-drive following stroke using the Occupational Therapy - Driver Off 
Road Assessment Battery. Disability and Rehabilitation, 41(15), 1797-1802.

doi:10.1080/09638288.2018.1445784

Vrkljan, B. H., McGrath, C. E., \& Letts, L. J. (2011). Assessment tools for evaluationg fitness to drive: A critical appraisal of evidence. Canadian Journal of Occupational Therapy, 78, 80-96. doi:10.2182/cjot.2011.78.2.3

Wheatley, C. J., Pellerito, J. M., \& Redepenning, S. (2006). The clinical evaluation. In J. M. Pellerito Jr (Ed.), Driver rehabilitation and community mobility: Principles and practice (pp. 103-116). St. Louis, MO: Mosby Elsevier.

Wooden, A. M. (2013). Stroke. In Latham, C. T., \& Radomski, M. V. (Eds.), Occupational therapy for physical dysfunction. (pp. 999-1041) Philadelphia Wolters Kluwer Health/Lippincott Williams \& Wilkins [2013].

Wynne, R. A., Beanland, V., \& Salmon, P. M. (2019). Systematic review of driving simulator validation studies. Safety Science, 117, 138-151.

doi:https://doi.org/10.1016/j.ssci.2019.04.004 
Appendix A

\section{JUIVERSITY OF ST. AUGUSTINE OGCUPATIONAL THERAPY PROGRAM RESEARCH STUDY}

\section{TITLE:}

Exploring the Goncurrent Validity of the Indoor Mobility Pre-driving Screen [IMPS]: A Comparison of the IMPS and EF-Gar Motion Driving Simulator

\section{WHERE?}

The University of St. Augustine 1 University BIvd, St. Augustine

HOW LONG WILL IT TAKE?

Participation will take approximately one hour during which you will fill out a demographic form, an informed consent waiver, and complete two assessments.

\section{IF YOU ARE INTERESTED CONTACT:}

NICHOLAS BOLEN

PHONE: [352] 283-9150

EMAIL: N.BOLEN@USA.EDU

\section{ASSESSMENT}

DETAIIS

Both assessments are conducted in-clinic. No on the road driving will oceur during uarticipation.

gONFIDENTIAITY All information will be kept confidential and will not be shared with the DMV or any other organization.

BEMEFIS

Participants will receive a free uredriving assessment with two separate assessment tools.

IMGIUSION

GRIIERIA

-Ages $18+$ with a valid driver's license.

-Able to navigate a course 150 feet long. Icanes, walkers, and wheelchairs may be used if neededl

-Able to tolerate simulated driving for 15 minutes. 
Appendix B

\section{IRB}

University of St. Augustine for Health Sciences

Out of town: 1-800-241-1027 x1234, Local: 1-904-826-0084 x1234.

IRB Informed Consent Form, IRB \#

\section{CONSENT FOR RESEARCH PARTICIPATION}

Title of Project: Exploring the Concurrent Validity of the Indoor Mobility Pre-driving Screen (IMPS): A Comparison of the IMPS and EF-Car Motion Driving Simulator.

IRB Number:

Principal Investigator: Dr. Kaitlyn Cremer, MOT, OTD, OTR/L, SCLV

(904) 770-3527

kcremer@usa.edu

1 University Blvd, St. Augustine, FL 32086

Co-Investigator: Nicholas Bolen, OTS

(352) 283-9150

n.bolen@usa.edu

1 University Blvd, St. Augustine, FL 32086

You are being asked to participate in a research study. The box below highlights key information about this research for you to consider when making a decision whether or not to participate. Carefully consider this information and the more detailed information provided below the box. Please ask questions about any of the information you do not understand before you decide whether to participate.

\section{Key Information for You to Consider}

- Voluntary Consent. You are being asked to volunteer for a research study. It is up to you whether you choose to participate or not. There will be no penalty or loss of benefits to which you are otherwise entitled if you choose not to participate or discontinue participation.

- Purpose. The purpose of this research is to explore the concurrent validity of the Indoor Mobility Pre-driving screen (IMPS). This is a comparison study between two assessments, the IMPS and the EF-Car Motion Driving Simulator. Data collected during the course of this study will be analyzed to see if a relationship exists between the two assessments.

- Duration. It is expected that your participation will last approximately 1 hour. 
- Procedures and Activities. You will be asked to complete this form, a demographic information form, and complete two assessments (IMPS and EF-Car Motion Driving Simulator.)

- Risks. Some of the foreseeable risks or discomforts of your participation include: Falling while navigating the environment, motion sickness, emotional distress if you do not score as well as you would like to.

- Benefits. Some of the benefits that may be expected include an increased understanding of my pre-driving abilities and knowledge of what my deficits are.

- Alternatives. Participation is voluntary and the alternative is to be evaluated by an occupational therapist or driving rehabilitation specialist not associated with this study.

\section{Why is this research being done?}

The purpose of this study is to compare two assessments, the IMPS and the EF-Car Motion Driving Simulator. Completion of this study will allow the researchers to examine the relationship between the scores of the two assessments. The hope is to further prove that the IMPS is a valid assessment for screening pre-driving skills.

\section{What Will Happen in This Research Study}

First, you will be asked to complete a demographic form. Following completion of the form, you will then complete two assessments, the IMPS and the EF-Car Motion Driving Simulator. The IMPS will require you to navigate a 125-175 feet course while identifying signs posted along the route which will take approximately 10 minutes. The EF-Car Motion Driving Simulator will assess your pre-driving skills through 3 different programs. Completion of these programs will take approximately 20-30 minutes. After completion of these two assessments, your participation will conclude.

The ways we will protect your privacy and confidentiality are described in a separate section later in this form.

We may make a video recording of you completing each assessment if you allow us. Do you grant permission for us to make a video recording of you?

$\square$ YES $\quad \square$ NO Initial

\section{$\underline{\text { Risks and Discomforts }}$}

There are no anticipated risks associated with this study and every attempt will be made to ensure your safety throughout the entirety of the testing process. Potential risks include experiencing motion sickness during completion of the driving simulator. Additionally, you could trip and fall while walking on the premises of the university and while completing the IMPS. If this were to happen, a medical professional should be contacted immediately. You may experience emotional distress if your results indicate you should receive further testing for community mobility/driving safety. Resources to improve or further assess your driving skills will be provided to you upon completion of the study at your request. There is no financial risk to you aside from loss of approximately 1 hour of your time.

\section{Potential Benefits}


The benefits of being in this study may be: gaining insight into your pre-driving skills and how you might perform while on the road. However, you may not receive any benefit. Your being in the study may help the investigators learn about the relationship between the IMPS and the EF-Car Motion Driving Simulator and assist with proving its validity.

\section{Alternatives}

The following alternative procedures or treatments are available if you choose not to be in this study: screening by an occupational therapist or certified driving rehabilitation specialist (CRDS) not involved in this study to assess your pre-driving skills.

\section{$\underline{\text { Costs }}$}

There are no costs to you for being in this research study aside from approximately 1 hour of your time.

\section{Payment}

You will not be paid for being in this study.

\section{Confidentiality}

We must use information that shows your identity to do this research. Information already collected about you will remain in the study record even if you later withdraw.

We will store your information in ways we think are secure. We will store paper files in locked filing cabinets until secured electronically. All of your information will be stored electronically and they physical copies destroyed. We will store electronic files on a password protected computer and in password protected folder. For example, this form (once completed) will be scanned and saved in a password protected folder. The physical form will then be destroyed. However, we cannot guarantee complete confidentiality.

If you agree to be in the study and sign this form, we will share information that may show your identity with the following groups of people:

- People who do the research or help oversee the research, including safety monitoring.

- People from Federal and state agencies who audit or review the research, as required by law. Such agencies may include the U.S. Department of Health and Human Services, the Food and Drug Administration, the National Institutes of Health, and the Massachusetts Department of Public Health.

- Any people who you give us separate permission to share your information.

We will share research data where we have removed anything that we think would show your identity. There still may be a small chance that someone could figure out that the information is about you. Such sharing includes:

- Publishing results in a professional book or journal.

- Adding results to a Federal government database. 
- Using research data in future studies, done by us or by other scientists.

\section{Subject's Rights}

By consenting to be in this study you do not waive any of your legal rights. Consenting means that you have been given information about this study and that you agree to participate in the study. You will be given a copy of this form to keep.

If you do not agree to be in this study or if at any time you withdraw from this study you will not suffer any penalty or lose any benefits to which you are entitled. Your participation is completely up to you. Your decision will not affect your ability to get health care or payment for your health care. It will not affect your enrollment in any health plan or benefits you can get.

We may decide to have you stop being in the study even if you want to stay. Some reasons this could happen are if staying in the study may be bad for you, or if the study is stopped.

\section{Questions}

The investigator or a member of the research team will try to answer all of your questions. If you have questions or concerns at any time, contact Nicholas Bolen at (352) 283-9150. Contact Kaitlyn Cremer at (904) 770-3527 if there is no answer at that phone number or if you are calling after normal business hours.

You may also call 737-202-3343 or email eardolino@usa.edu. You will be talking to Elizabeth Ardolino, the chairperson of the IRB at the University of St. Augustine for Health Sciences. The IRB is a group that helps monitor research. You should call or email the IRB if you want to find out about your rights as a research subject. You should also call or email if you want to talk to someone who is not part of the study about your questions, concerns, or problems. 
Subject:

Printed name of subject

By signing this consent form, you are indicating that

- you have read this form (or it has been read to you)

- your questions have been answered to your satisfaction

- you voluntarily agree to participate in this research study

- you permit the use and release of information that may identify you as described including your health information.

To be completed by subject if personally signing

Signature of subject

Date

To be completed by LAR if subject does not personally sign

I am providing consent on behalf of the subject.

Printed name of Legally Authorized Representative (LAR)

Relationship to Subject

Signature of Legally Authorized Representative

Date

Researcher:

Printed name of person conducting consent discussion

To be completed by researcher if subject personally signs

I have personally explained the research to the above-named subject and answered all questions. I believe that the subject understands what is involved in the study and freely agrees to participate.

Signature of person conducting consent discussion

Date

To be completed by researcher if subject does not personally sign

I have personally explained the research to the above-named subject's Legally Authorized

Representative and answered all questions. I believe that the Legally Authorized Representative understands what is involved in the study and freely agrees to have the subject participate.

I consider that the above-named subject (check one):

$\square$ is capable of understanding what is involved in the study and freely agrees to participate.

$\square$ is not capable of understanding what is involved in the study.

Signature of person conducting consent discussion

Date 
To be completed by witness if researcher reads this form to the subject/LAR

This consent form was read to and apparently understood by the subject/Legally Authorized Representative in my presence.

Printed name of witness (a person not otherwise associated with the study)

Signature of witness

Date

THIS PROJECT HAS BEEN REVIEWED AND APPROVED BY THE UNIVERSITY OF ST. AUGUSTINE FOR HEALTH SCIENCES INSTITUTIONAL REVIEW BOARD FOR THE PROTECTION OF HUMAN SUBJECTS.

IF YOU HAVE QUESTIONS OR CONCERNS, PLEASE CONTACT THE INSTITUTIONAL IRB CHAIR, DR. ELIZABETH ARDOLINO, EMAIL: EARDOLINO@USA.EDU, PHONE: 737-202-3343. 
Appendix $\mathrm{C}$

\section{DEMOGRAPHICS FORM}

Name:

Height:

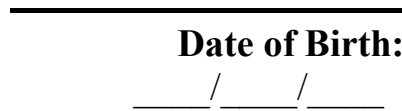
Gender:
Male Female

Hand Dominance:

Right Left

Email Address:

Is English your first language? $\square$ Yes $\square$ No

MEDICAL HISTORY: Do have a history of any of the following conditions? (Check all that apply):

Vision problems (Circle all that apply): glaucoma, cataracts, wear glasses

Hypertension (High blood pressure)

Diabetes

Traumatic Brain Injury/Cerebral Palsy

Stroke/ Heart Problems

Other, please list below:

Sensory problems (Numbness or tingling in arms or legs)

Orthopedic problems

$\square$ Arthritis/Joint problems

$\square$ Cognitive or memory problems

$\square$ Neurological Conditions (Multiple Sclerosis, Parkinson's, Spina Bifida, Spinal Cord Injuries)

DRIVING HISTORY: Please Answer The Following Questions:

1. Do have a driver's license?

2. If so, what state and license class?

3. Do you currently drive?

4. How many years have you been driving?

5. Approximately how many days a week do you drive?

6. Approximately how long (time) do you drive per trip?

8. For what purposes do you typically drive? Please check all that apply:

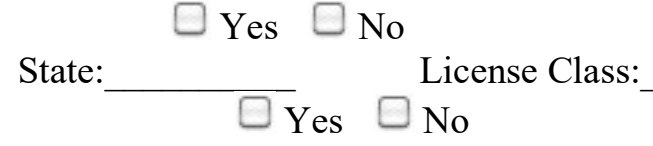

7. Approximately how far (miles) do you drive
in a typical day?

Work/School Errands/Shopping

Pleasure/Leisure/Social

Other

$\square$ Driving Others

Doctor Appointments

9. How would describe the types of roads you usually drive? Please check all that apply:

\section{City Streets}

Highways
Turnpikes

$$
\text { Turnpikes }
$$

10. Do you have trouble seeing while driving?

Other

11. If yes, when do you have the most trouble seeing while driving? Please check all that apply:
Daytime
Nighttime
Rain
Rain

12. Do you wear glasses or contacts while you drive?

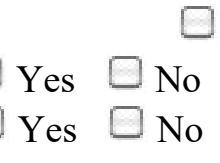


THIS PROJECT HAS BEEN REVIEWED AND APPROVED BY THE UNIVERSITY OF ST. AUGUSTINE FOR HEALTH SCIENCES INSTITUTIONAL REVIEW BOARD FOR THE PROTECTION OF HUMAN SUBJECTS.

IF YOU HAVE QUESTIONS OR CONCERNS, PLEASE CONTACT THE INSTITUTIONAL IRB CHAIR, DR. ELIZABETH ARDOLINO, EMAIL: EARDOLINO@USA.EDU, PHONE: 737-202-3343. 


\section{Appendix D}

\section{Indoor Mobility Pre-Driving Screen}

\section{Instructions and Score Form}

Purpose: The Indoor Mobility Pre-driving Screening (IMPS) is an indoor mobility tool used to screen for driving readiness. The is an in-clinic screening tool developed to assess pre-driving abilities of individuals with various diagnoses. The IMPS incorporates measurements of dynamic vision and the ability to move through space into the screening process. The screen is designed to quickly screen the abilities required for driving and community mobility including memory, alternating/divided attention, problem solving, mobility: head control/movement, visual scanning at midline, scanning of right visual field, scanning of left visual field, acting on informational signs, way finding, and accuracy.

Materials required: Index cards, tape, stop watch, measuring tape initially, Test form, Score form

Course set up:

- Starting Location: To be determined by therapist

- Destination: Minimum of 125 feet and maximum of 175 feet from starting location

Course requirements:

- Test must have at least one turn to the right and one turn to the left

- The course should have five signs on the right, five signs on the left, and three signs at midline. With at least one midline sign being a directional sign.

- The signs should be evenly spaced throughout the course and placed at "eye" level. Note: You can lower signs if client is at a w/c level 
Course Map Examples:
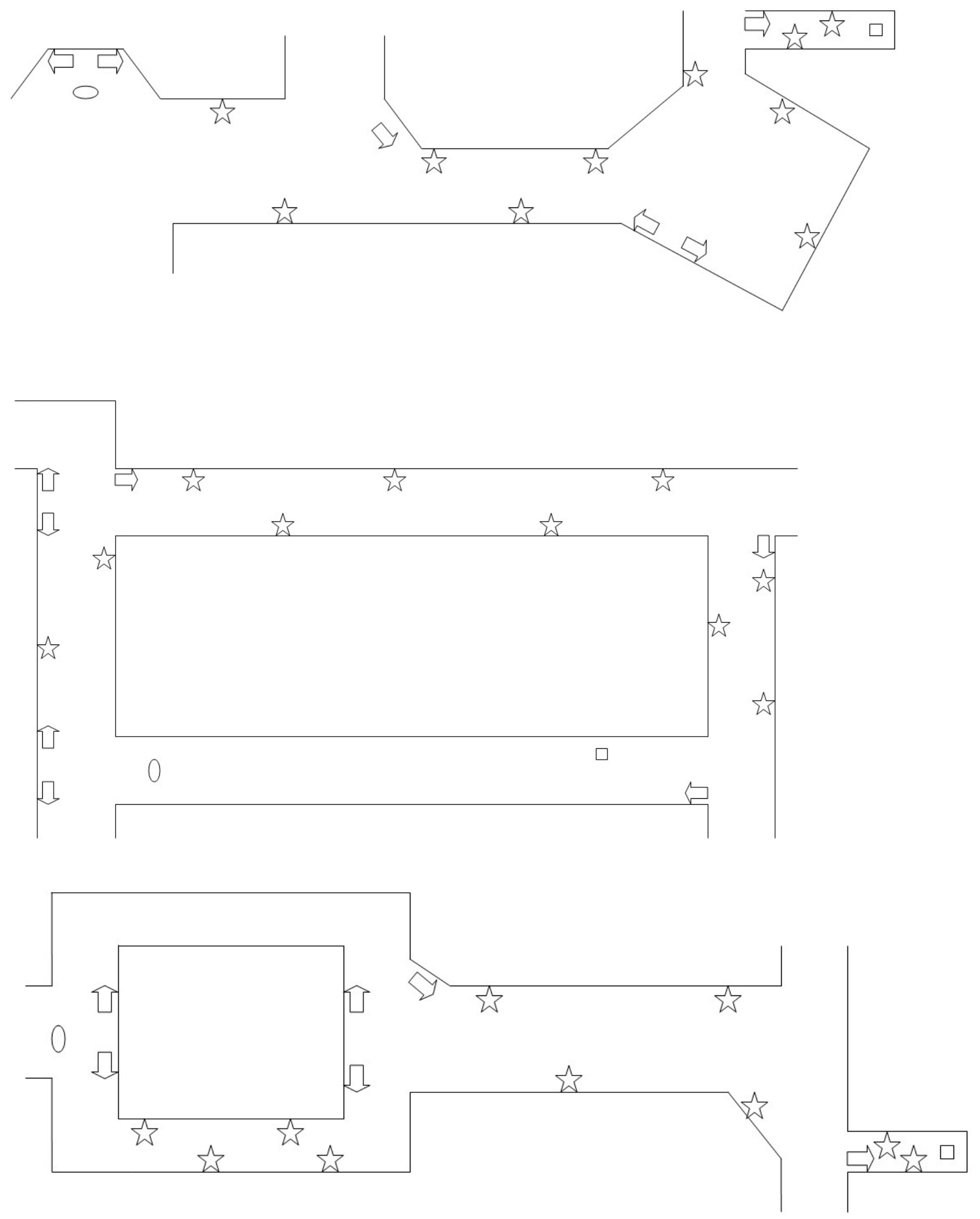


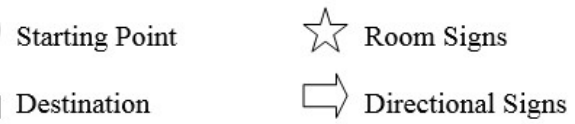

Script:

"The purpose of this assessment is to screen you for your ability to move through an environment, find your way, and be aware of objects around you."

"In this test, you will follow the signs to find your way to a location marked 'destination' in this building.

- You will not have to open any doors.

- While you are looking for the "destination", I want you to call out and read aloud every one of the white signs that you see (SHOW INDEX CARDS).

- Ignore all of the signs that are not like these (SHOW INDEX CARDS) for example, ignore the typical room, exit, or rest room signs.

- These white signs may be on the right or left side or in front of you.

- The white index card signs may have words, numbers, or arrows on them like these (SHOW samples of each type of card).

- The last thing I want you to do is come back to this starting point by reversing the directions, while you call out the signs you see on your way back to this starting point.

*So, just to review the instructions:

- Find the location marked 'destination'

- Call out and point to every white sign along the way and on the way back to the start

- Come back to the starting location.

Do you have any questions?"

Answer and discuss as needed.

"Would you repeat the directions out loud to me?"

- Repeat directions until patient can list the 3 parts of instructions (as above)

- Note on IMPS Test Form how many repetitions required until client repeats the three critical instructions (as above).

(Place gait belt on client prior to testing). "I will be using this gait belt to insure your safety". Have patient stand at the starting location (show patient visual target example again).

- 'I'm going to time you and take notes.

- Proceed as quickly as possible, but take as much time as you need to insure your safety.

- When you pass the sign labeled 'Start' (point to start sign), timing will begin.

- Remember that the signs look like this (point again).

- Start when you are ready." 


\begin{tabular}{|c|c|c|c|}
\hline \multicolumn{4}{|c|}{ Indoor Mobility Pre-Driving Skills Test Form } \\
\hline \multicolumn{2}{|l|}{$\begin{array}{l}\text { Patient /Client Name: } \\
\text { Diagnosis(es): }\end{array}$} & \multicolumn{2}{|l|}{$\begin{array}{l}\text { Date of Birth: } \\
\text { Date of IMPS: }\end{array}$} \\
\hline \multicolumn{4}{|c|}{ Directions: Number of repetitions to repeat directions } \\
\hline $\begin{array}{l}\text { Visual Targets from Home to } \\
\text { Destination: Check each target } \\
\text { identified } \\
\text { One verbal cue allowed } \\
\text { immediately after first omission: } \\
\text { "Remember to point out and } \\
\text { read the signs." }\end{array}$ & $\begin{array}{l}\text { Left: } \\
\square_{\mathrm{rm} 103} \\
\square_{\mathrm{rm} 105} \\
\square_{\mathrm{rm} 107} \\
\square_{\mathrm{rm} 109} \\
\square_{\text {restroom }}\end{array}$ & $\begin{array}{l}\text { Midline: } \\
\square \text { Destination } \\
\square \text { Right Arrow } \\
\square \text { Left Arrow }\end{array}$ & $\begin{array}{l}\text { Right: } \\
\square \text { rm } 104 \\
\square \text { rm } 106 \\
\square \text { rm } 108 \\
\square \text { rm } 110 \\
\square \text { janitor }\end{array}$ \\
\hline Destination: & \multicolumn{3}{|c|}{$\begin{array}{l}\text { Found Destination Independently } \\
\text { Difficulty Finding Destination Due To: } \\
\square \text { Not Reading or Following Destination Signs } \\
\square \text { Missed Turns: } \\
\text { Left: } \quad / 1 \text { Right: } \quad / 2 \\
\square \text { Not Attending to Left/Right Side } \\
\text { \# of Verbal Cues to Complete Route }\end{array}$} \\
\hline \multicolumn{4}{|l|}{ Time from Start to Destination: } \\
\hline $\begin{array}{l}\text { Return Route: } \\
\text { Initiation: If patient is not } \\
\text { initiating the next step, one verbal } \\
\text { prompt is allowed: } \\
\text { "Now find the room we started } \\
\text { in." }\end{array}$ & \multicolumn{3}{|c|}{$\begin{array}{l}\square \text { Found Starting Location Independently } \\
\text { Difficulty Finding Starting Location Due To: } \\
\square \text { Missed Turns: } \\
\text { Left: } \\
\square \text { Wrong Turns } \\
\square \text { Not Attending to Left/Right Side } \\
\square \text { Cannot Start to Retrace Route } \\
\square \text { Cannot Recall Starting Location } \\
\text { "Start walking and let's see if you recognize it." } \\
\text { \# of Verbal Cues to Complete Return Route }\end{array}$} \\
\hline $\begin{array}{l}\text { Visual Targets from Destination } \\
\text { to Home: Check each target } \\
\text { identified }\end{array}$ & $\begin{array}{l}\text { Left: } \\
\square \text { janitor } \\
\square \text { rm } 110 \\
\square \text { rm } 108 \\
\square \text { rm } 106 \\
\square \text { rm } 104\end{array}$ & $\begin{array}{l}\text { Midline: } \\
\square \quad \text { Left Arrow } \\
\square \quad \text { Right Arrow } \\
\square \quad \text { Left Arrow }\end{array}$ & $\begin{array}{l}\text { Right: } \\
\square \text { restroom } \\
\square \text { rm } 109 \\
\square \text { rm } 107 \\
\square \text { rm } 105 \\
\square \text { rm } 103\end{array}$ \\
\hline Time from Destination to Start: & & & \\
\hline
\end{tabular}




\section{Indoor Mobility Pre-Driving Skills Score Form}

Date:

Patient Name/Number:

MEMORY:

4 - Verbalized 3-part instructions without repetition, did not need verbal cue to point out visual targets, remembered destination and return route without cues

3 - Required 1 of the following: repetition of instructions before able to verbalize them, 1 verbal cue to point out visual targets, 1 verbal cue to start return route, unable to recognize starting location independently

2 - Required 2 of the following: repetition of instructions before able to verbalize them, 1 verbal cue to point out visual targets, 1 verbal cue to start return route, unable to recognize starting location independently

1 - Required 3 or more of the following: repetition of instructions before able to verbalize them, 1 verbal cue to point out visual targets, 1 verbal cue to start return route, unable to recognize starting location independently

0 - Unable to verbalize 3-part instructions (or identify in forced choice, or write if aphasic) after 3 repetitions, required more than 1 cue to point out visual targets, unable to recognize starting location

\section{ALTERNATING/DIVIDED ATTENTION:}

Total Memory

3 - Found destinations and pointed out correct visual targets without cues or errors

2- Required 1-2 verbal cues to point out visual targets while searching for destination(s)

1 - Required 3-4 verbal cues to point out visual targets while searching for destination(s)

0 - Unable to point out visual targets while moving through space and searching for destination(s)

PROBLEM SOLVING:

Alternating/Divided Attention $/ 3$ pt.

3 - Found destination and starting location independently

2 - Required 1 verbal cue to problem-solve to begin route and or able to correct self when took a wrong turn(s)

1 - Required 2 or more verbal cues to problem solve to begin route and or able to correct self when took a wrong turn(s)

0 - Unable to start in any direction despite 2 or more verbal cues

\section{MOBILITY: HEAD CONTROL/MOVEMENT:}

Problem Solving _ $/ 3$ pt.

3 - Able to move through space without bumping into objects/people and able to maintain head within 20 degrees of central visual field with minimal head turning in all visual planes for adequate visual search

2 - One near miss, i.e. almost bumped into object/person and or not able to maintain head within 20 degrees of central visual field $25-50 \%$ of the time

1 - Two or more near misses and or not able to maintain head within 20 degrees of central visual field $50-75 \%$ of the time

0 - Bumped into any object/person or required intervention to avoid bumping and or not able to maintain head within 20 degrees of central visual field approximately $100 \%$ of the time and as a consequence missed 1 or more of the following: visual targets or destinations

VISION/SCANNING AT MIDLINE:

\section{Mobility/Head Control} $/ 3$ pt.

2 - Able to locate all directional signs and destinations appearing in midline without delay or cues

1 - Misses 1 visual target or directional sign in midline, or misses destination(s) appearing in midline

0 - Misses 2 or more visual targets or directional signs, or misses destination(s) appearing in midline

VISION/SCANNING RIGHT FIELD:

Scanning midline $/ 2$ pt.

2 - Able to locate all visual targets and destinations appearing in right visual field without delay or cues, and avoids extraneous visual distractions

1 - Misses 1 visual target in right visual field, or misses destination(s) appearing in right visual field

0 - Misses 2 or more visual targets or destinations appearing in right visual field

\section{VISION/SCANNING LEFT FIELD:}

Scanning right 12 pt.

2 - Able to locate all visual targets and destinations appearing in left visual field without delay or cues, and avoids extraneous visual distractions

1 - Misses 1 visual target in left visual field, or misses destination(s) appearing in left visual field

0 - Misses 2 or more visual targets or destinations appearing in left visual field 


\section{ACTING ON INFORMATIONAL SIGNS:}

3 - Located directional signs without delay, read and followed sign information

2 - Missed directional signs initially, but then located and followed sign information

1 - Missed directional signs, unable to locate either destination or starting location

0 - Missed directional signs, unable to locate destination and starting location without verbal cues

\section{WAYFINDING:}

Acting on Informational signs

13 pt.

5 - Found destination and starting location independently without wrong turns

4 - Found destination and starting location independently with 1 or more wrong turn(s) but no cues from therapist

3 - Found destination and starting location with 1 or more wrong turn(s) and 1 cue from therapist

2 - Found destination and starting location with 1 or more wrong turn(s) and 2 or more cues from therapist

1 - Required 1 or more cues to find destination and unable to find starting location

0 - Unable to find destination and or starting location with 2 or more cues

\section{ACCURACY:}

Number of visual targets identified en route to destination (12 possible points)

Number of visual targets identified en route to starting location (12 possible points)

Number of visual targets identified in right visual field en route to destination AND in return to start (10 possible points)

Number of visual targets identified in left visual field en route to destination AND in return to start (10 possible points)

Number of visual targets identified at midline visual field en route to destination AND in return to start (4 possible points)

\section{Time}

Accuracy

148 pt.

Time to destination (in seconds)

Time back to start (in seconds)

TOTAL

\section{Qualitative Indicators}

\section{Cues Were Required Because Of:}

Right visual neglect

Left visual neglect

Visual scanning difficulties

Unable to see visual targets

Limited head mobility

Memory impairment or loss

\section{Decreased attention}

Fatigue

Loss of interest

Distracted by external stimuli

Unable to understand instructions

Other 


\section{Score Summary}

\begin{tabular}{|l|l|}
\hline Memory & \\
\hline Alternating Attention & \\
\hline Problem Solving & \\
\hline Mobility/Head Control and Head Movement & \\
\hline Vision/Scanning at Midline & \\
\hline Vision/Scanning Right Field & \\
\hline Vision/Scanning Left Field & \\
\hline Acting on Informational Signs & \\
\hline Way Finding & \\
\hline Accuracy: En Route to Destination & \\
\hline Accuracy: En Route To Starting Location & \\
\hline Accuracy: Right Visual Field & \\
\hline Accuracy: Left Visual Field & \\
\hline Accuracy: Midline & \\
\hline Total Score & \\
\hline
\end{tabular}




\section{Signed Faculty Signature Page}

Exploring the Concurrent Validity of the Indoor Mobility Predriving Screen (IMPS): A Comparison of the IMPS and EF-Car Motion Driving Simulator.

by

Nicholas Bolen

has been approved

April 2020

APPROVED:

KAYLA COLLINS, MOT, Ed.D, OTR/L, Doctoral Coordinator

ACCEPTED AND SIGNED: Kayla Callens

KAYLA COLLINS, MOT, Ed.D., OTR/L 